ROBERT M. COEN

Northwestern University

BERT G. HICKMAN

Stanford University

\title{
Keynesian and Classical Unemployment in Four Countries
}

THE WORLD ECONOMY entered a period of stagflation during the 1970s. Markedly slower growth combined with rates of unemployment and inflation that were unprecedentedly high for the postwar era, and the slowdown persists to this day. In this paper we draw on a larger study of the deceleration of potential growth to emphasize the contributory role of demand shortfalls in prolonging and deepening the adjustment to lower growth rates of productivity and real wages. A key issue is the relative importance of high real wages and deficient aggregate demand as proximate causes of the rise of unemployment.

We use the theoretical approach developed by Hickman to estimate the classical and Keynesian components of excess unemployment in the United States, Germany, Austria, and the United Kingdom. ${ }^{1}$ The approach is closely related to the "wage gap" analysis of Michael Bruno

This paper is part of a research project on unemployment, real wages, and economic growth in selected OECD countries. The support of the Austrian National Bank is gratefully acknowledged. We are indebted to the Brookings Panel and to Erich Streissler, Stefan Schleicher, Stephen King, George Evans, Jean Waelbroeck, and seminar participants at the University of Vienna, Project LINK, and Stanford University for their comments and suggestions. Thanks are also due to Christian Stadlinger for his valuable assistance.

1. Bert G. Hickman, "Real Wages, Aggregate Demand, and Unemployment" (Center for Economic Policy Research, Stanford University, July 1986). Forthcoming in European Economic Review. 
and Jeffrey Sachs, but it differs in building on the assumption of imperfect competition and cost minimization rather than perfect competition and profit maximization as the basis for labor demand. ${ }^{2}$ Similarly, it differs from the general disequilibrium or non-market-clearing models of Robert Barro and Herschel Grossman and Edmond Malinvaud in that it allows for coexistence of classical and Keynesian unemployment instead of explaining them as separate regimes in markets with price-taking firms and rationed buyers and sellers. ${ }^{3}$

Our empirical measures of the wage and demand components of employment are computed from a conditional demand function for aggregate man-hours, with the real wage and output treated as predetermined to the employment decisions of firms. Since the real wage and aggregate demand are in reality endogenous variables, the decomposition deals only with their relative importance as proximate sources of unemployment. A deeper approach would employ a complete macroeconomic model endogenizing aggregate output and real wages and capable of explaining the evolution of both as a function of exogenous shocks to aggregate supply and demand, as recommended by Robert Solow. ${ }^{4}$ That would be feasible in our U.S. model, which is just such a complete system, but not in the truncated supply-side models we have estimated for the European countries in the study.

\section{Concepts of Keynesian and Classical Unemployment}

The standard fixed-price or non-market-clearing model distinguishes Keynesian and classical unemployment states as separate regimes under fixed wage and price levels by incorporating quantity constraints into the optimization problems of firms and households. ${ }^{5}$

2. Michael Bruno and Jeffrey D. Sachs, Economics of Worldwide Stagflation (Harvard University Press, 1985).

3. Robert J. Barro and Herschel I. Grossman, "A General Disequilibrium Model of Income and Unemployment," American Economic Review, vol. 61 (March 1971), pp. 8293; Edmond Malinvaud, The Theory of Unemployment Reconsidered (Oxford: Basil Blackwood, 1977).

4. Robert M. Solow, "Unemployment: Getting the Questions Right," Economica, vol. 53 (Supplement, 1986), pp. S23-S34.

5. Basic references include Don Patinkin, Money, Interest and Prices: An Integration of Monetary and Value Theory, 2d ed. (Harper and Row, 1965); Robert Clower, "The 
The representative firm is a price taker in its markets for inputs and output. It maximizes profits subject to a well-behaved production function, $Y=F(K, L)$, and a product demand constraint, $Y \leq \bar{Y}$. For fixed $K$ in the short run, the optimal solution for $L$ is the min-equation

$$
L^{d}=\min \left[F^{-1}(\bar{Y}, \bar{K}), F_{L}^{-1}(W / P, \bar{K})\right],
$$

where $W / P$ is the real product wage.

The unconstrained or notional short-run functions for labor demand and product supply are

$$
L^{d}=F_{L}^{-1}(W / P, \bar{K}),
$$

given by the first-order marginal productivity condition, and

$$
Y^{s}=F\left(L^{d}, \bar{K}\right) .
$$

The classical labor supply function is

$$
L^{s}=L^{s}(W / P),
$$

where the real wage equates the marginal disutility of effort and the marginal utility of consumption.

With flexible wages and prices, a Walrasian solution of equations 2 and 4 would yield full employment at the equilibrium real wage. With fixed wages and prices, however, if notional supply exceeds effective demand at the given price, the sales of firms are rationed in the product market. Labor demand is then output-constrained and is smaller than labor supply at the existing real wage, resulting in Keynesian unemployment:

$$
L^{d}=F^{-1}(\bar{Y}, \bar{K})<L^{s}(W / P) .
$$

Thus Keynesian unemployment is the spillover effect of disequilibrium in the product market.

Classical unemployment may occur if the fixed price is below the Walrasian equilibrium level. Effective demand then exceeds notional

Keynesian Counterrevolution: A Theoretical Appraisal," in F. H. Hahn and F. P. R. Brechling, eds., The Theory of Interest Rates (London: Macmillan, 1965), pp. 103-25; Barro and Grossman, "A General Disequilibrium Model"; Malinvaud, The Theory of Unemployment Reconsidered; Jean-Pascal Benassy, "Neo-Keynesian Disequilibrium Theory in a Monetary Economy," Review of Economic Studies, vol. 42 (October 1975), pp. 503-23; Jean-Pascal Benassy, The Economics of Market Disequilibrium (Academic Press, 1982). 
supply. Firms have no incentive to increase supply at the existing real wage, so the short side of the market prevails and households are rationed. Firms are unconstrained and operating on their notional labor demand and output supply schedules, but since the real wage exceeds the Walrasian level, labor demand falls short of full-employment labor supply.

In both unemployment states households are constrained in the labor market, and hence effective demand falls short of the notional demand that would result from unconstrained utility maximization. Indeed, as Robert Clower showed, it is because of the spillover from the labor market constraint that income is an argument in the consumption function. ${ }^{6}$

However, the approach of this paper modifies the standard fixedprice model, in which prices are fixed over the period being analyzed, in two principal respects. First, we assume imperfect competition with firms setting prices in the face of uncertain demand. We assume that prices are not continually adjusted. Second, firms choose capital and labor inputs so as to minimize the cost of producing the quantity they expect to sell at the price they have set.

The assumption of imperfect competition is adopted for both theoretical and empirical reasons. Perfect competition among atomistic pricetaking firms is incompatible with the fixed-price assumption except for very short adjustment periods after unexpected shocks. As an empirical matter, moreover, auction markets are largely limited to agricultural products and primary metals. There is also solid econometric evidence of the ubiquitous existence of cost-based price setting, with only a limited scope for markup variations in response to shifts in product demand. ${ }^{7}$

One important consequence of cost-based price setting is that it reduces the sensitivity of real wages to changes in effective demand. Increases or decreases in nominal wages induced by shifts in aggregate demand induce price movements in the same direction, greatly mitigating the response of real wages to demand pressures in labor markets. In contrast, supply shocks that directly raise production costs, such as the

6. Clower, "The Keynesian Counterrevolution."

7. Otto Eckstein, ed., The Econometrics of Price Determination, conference sponsored by Board of Governors of the Federal Reserve System and Social Science Research Council (Board of Governors, 1972); Phillip Cagan, "The Hydra-Headed Monster: The Problem of Inflation in the United States, ' Domestic Affairs Study 26 (Washington, D.C.: American Enterprise Institute, 1974); William D. Nordhaus, "The Falling Share of Profits," BPEA, 1:1974, pp. 169-208. 
energy shocks of the 1970 s, have greater potential to alter real wage rates unless they are offset by prompt and substantial wage indexation.

As a corollary to real wage inflexibility under markup pricing, macroeconomic models, including our own, that incorporate the hypothesis generally depend for their equilibrating properties on absolute variations in the wage-price level, operating through the Phillips curve and markup mechanisms. In the standard textbook $I S-L M$ model, for example, restoration of long-term equilibrium after a shock depends on priceinduced changes in the real money supply and interest rates. ${ }^{8}$ In some of the larger econometric models, real wealth arguments in the aggregate demand functions are also involved. ${ }^{9}$

Market imperfections provide a theoretical rationale for the fixedprice assumption. One theoretical rationale is the perceived asymmetry of competitors' responses to a firm's potential price increase or decrease in oligopolistic industries as the source of price rigidity, as in Paul Sweezy's theory of the kinked demand curve. ${ }^{10}$ Similarly, in Takashi Negishi's conjectural equilibrium model of atomistic firms, a kink in the perceived demand schedule exists because of the asymmetric reactions of consumers to price changes: "Lower prices asked by a supplier may not be fully advertised to customers currently buying from other suppliers who are maintaining their current price, while a higher price charged by the same supplier necessarily induces present customers to leave in search of lower price suppliers." "II Imperfect information and search

8. See, for example, Rudiger Dornbusch and Stanley Fischer, Macroeconomics, 3d ed. (McGraw-Hill, 1984); Robert J. Gordon, Macroeconomics, 3d ed. (Little, Brown, 1984); Robert Hall and John Taylor, Macroeconomics: Theory, Performance, and Policy (Norton, 1985).

9. The equilibrating mechanisms in empirical multinational models are discussed in Bert G. Hickman, The U.S. Economy and the International Transmission Mechanism: A Structural Comparison of Twelve Multicountry Models, CEPR Publication 78 (Center for Economic Policy Research, Stanford University, 1986); those in U.S. econometric models are discussed in Hickman, "Macroeconomic Effects of Energy Shocks and Policy Responses: A Structural Comparison of Fourteen Models" (Energy Modeling Forum, Stanford University, 1984).

10. Paul M. Sweezy, "Demand under Conditions of Oligopoly," Journal of Political Economy, vol. 47 (August 1939), pp. 568-73.

11. Takashi Negishi, Microeconomic Foundations of Keynesian Macroeconomics (Amsterdam: North-Holland, 1979), p. 87. Frank H. Hahn's model of conjectural equilibrium is similar to Negishi's but does not assume a kink in the perceived demand curve. See Hahn, "Exercises in Conjectural Equilibria," Scandinavian Journal of Economics, vol. 79 (1977), pp. 210-26; Hahn, "On Non-Walrasian Equilibria," Review of Economic Studies, vol. 45 (February 1978), pp. 1-17. 
processes are also central to Arthur Okun's customer shopping model, with added stress on the desire of sellers to maintain strong long-term customer attachment to their products by forgoing price adjustments to temporary demand fluctuations. ${ }^{12}$ In all these formulations, shifts in demand initially lead to a change in the quantity sold at the current price and may leave the price permanently unaffected; thus they provide a justification for the fixed-price or rigid-price model that is used here.

Under imperfect competition, the firm expects to sell output $\bar{Y}$ when it sets price at $\bar{P}$. Expected revenue is predetermined, and the firm minimizes production costs to determine factor demands. For fixed $K$, $L$ will again be given by the inverted production function as in equation 5. If substitution of capital and labor is taken into account, however, the labor demand function becomes conditional on the wage-rental ratio as well as on output:

$$
L^{d}=L^{d}(W / Q, \bar{Y})
$$

The replacement of the inverted production function in equation 5 by the conditional labor demand function, equation 6 , is the key to the new method of allocating unemployment in this paper. Since the rental price of capital, $Q$, includes the price of capital goods $(P I)$ along with the discount and depreciation rates, labor demand depends on the real investment wage (W/PI), as well as on output, in contrast to the discrete classical and Keynesian dichotomy in equation 1. Labor demand can therefore fall short of full-employment labor supply because effective demand is too low or because the real wage is too high, or both. Keynesian and classical unemployment may coexist rather than occurring in separate regimes as in the standard fixed-price disequilibrium model. Classical unemployment is ruled out as a discrete state with firms on their notional supply schedules and households rationed off their demand schedules, but it may still occur in the absence of Keynesian unemployment provided that a positive wage gap-with the real wage above the full-employment level-exists without an accompanying demand shortfall.

We follow established terminology in referring to unemployment attributable to a positive wage gap as classical and unemployment due to deficient effective demand as Keynesian. It is true that our imperfectly

12. Arthur M. Okun, Prices and Quantities: A Macroeconomic Analysis (Brookings, 1981), p. 87. 
competitive setup allows for the coexistence of both components, but that is not fundamentally different from the Keynesian state of the competitive model, which requires only that firms be demand-constrained, so that employment is determined from the inverted production function under the min-condition in equation 1 . If, in addition to a binding demand constraint, the real wage also exceeds the Walrasian level in the competitive model, restoration of full employment will require that the real wage gap as well as the demand gap be eliminated. This is the distinction made by Barro and Grossman between Keynesian involuntary unemployment due to inadequate product demand with the real wage at or below the Walrasian level, and any latent classical involuntary unemployment due to a concurrent wage gap. ${ }^{13}$ Similarly, Jean Pascal Benassy notes that in the foregoing circumstance, it would be necessary to increase aggregate demand and decrease the real wage to suppress unemployment totally, so that "both classical and Keynesian measures would be necessary." 14

There are nonetheless important differences between the competitive model and our approach. In the classical unemployment regime of the competitive model, a positive real wage gap forecloses any increase of employment from expansionary demand policies. Excess demand exists for goods, and any additional demand stimulus could not improve employment, since profits are already maximized at the current wageprice configuration and capital stock. Similarly, if an inflexible wage gap accompanies the Keynesian demand-constrained regime, the classical component of excess unemployment cannot be eliminated by a demand stimulus.

In the imperfectly competitive model, by contrast, the labor demand function is shifted directly by changes in output, and hence the classical component of unemployment can be offset by high effective demand, as happened often in Austria and occasionally in the United States and Germany according to our empirical results. A positive wage gap is not necessarily an impenetrable barrier to eliminating excess unemployment by demand management, although there may be limitations and drawbacks to such a policy, as discussed later.

The difference in the assumption about whether the real wage affects output makes a big difference to the elasticity of employment with

13. Barro and Grossman, “A General Disequilibrium Model,” pp. 86-87.

14. Benassy, The Economics of Market Disequilibrium, p. 130. 
respect to the real wage. As will be shown later, employment is much more responsive to a wage change under the competitive case.

To elucidate key features of our approach, it is best to abstract from complicating aspects of the empirical models. Let us assume, for simplicity, that the full-employment labor supply is exogenously given. The magnitude of classical unemployment then depends on the size of the real wage gap and on the elasticity of labor demand with respect to the real wage. To establish the size of the wage gap, we must first determine the full-employment equilibrium value of the real wage and the corresponding level of output-that is, potential output. Our concept of full-employment equilibrium is based not on labor market clearance at a given capital stock, as in the short-run competitive model above, but on capital as well as labor market equilibrium. That is, it assumes that profits would be maximized if firms were operating at the fullemployment equilibrium. The full-employment real wage must be consistent not only with full employment of labor but also with attainment of a required marginal rate of return on capital.

The nature of the full-employment equilibrium is most transparent if we neglect technical progress and expectational and adjustment lags, all of which play important roles in our empirical models. As in the empirical models, we assume that the aggregate production function is CobbDouglas with constant returns to scale:

$$
Y=K^{\alpha} L^{1-\alpha} .
$$

Firms choose inputs to minimize costs, so that the optimal inputs satisfy the expansion path equation:

$$
W / Q=[(1-\alpha) / \alpha](K / L),
$$

where $Q$ is the implicit rental price of capital. If there are no taxes, and if there is a homogeneous output that can either be consumed or be used as capital, then $Q=P(R+d)$, where $P$ is the price of output, $R$ is the rate of return on capital, and $d$ is the depreciation rate. Then equation 8 can be written in terms of the real wage as

$$
W / P=[(1-\alpha) / \alpha](K / L)(R+d) .
$$

In an imperfectly competitive equilibrium, the value of output exceeds total factor costs, and national income can therefore be expressed as $P Y=\lambda[W L+Q K]$, where $\lambda>1$ and depends on the price elasticity 
of demand. Solving the national income equation for the rate of return, we obtain

$$
R=(P Y-\lambda W L-\lambda P d K) / \lambda P K=(Y / \lambda K)-(W L / P K)-d .
$$

Substituting from equation 9 for $(W L / P K)$ gives

$$
R=\alpha(Y / \lambda K)-d .
$$

Thus the net return $R$ equals the marginal revenue product of capital net of depreciation.

Setting $R=r$, the required rate of return, and $L=\bar{L}^{s}$, the given fullemployment labor supply, equations 7,9 , and 11 determine the fullemployment real wage, potential output, and potential capital, the latter being the capital stock that yields the return $r$ when employment is $\bar{L}^{s}$ and the real wage satisfies equation 9 . Denoting the solution values by asterisks, we have

$$
\begin{gathered}
Y^{*}=[\alpha / \lambda(r+d)]^{\alpha /(1-\alpha)} \bar{L}^{s} \\
K^{*}=[\alpha / \lambda(r+d)]^{1 /(1-\alpha)} \bar{L}^{s} \\
(W / P)^{*}=(1-\alpha)[\alpha /(r+d)]^{\alpha /(1-\alpha)}\left(\frac{1}{\lambda}\right)^{1 / 1-\alpha} .
\end{gathered}
$$

The smaller the required return on capital and the larger the fullemployment labor supply, the larger are potential output and capital stock. The equilibrium real wage also depends inversely on the required return, but it is independent of the exogenous labor supply. It is easy to show that the right-hand side of equation 14 equals the marginal revenue product of labor, $(1-\alpha)(Y / \lambda L)$.

The full-employment equilibrium is depicted graphically in figure $1 .{ }^{15}$ The isoquant labeled $Y_{0}^{*}$ refers to potential output and the equilibrium inputs are $K_{0}^{*}$ and $\bar{L}^{s}=L_{0}^{*}$, satisfying the cost-minimizing condition that the marginal rate of technical substitution between $L$ and $K$ equals the wage-rental ratio, $(W / P)^{*}[1 /(r+d)]$, or geometrically that the slope of the isoquant equals the slope of the isocost line tangent to it at point $A$. The ray through $A$ is the expansion-path locus for which the same factor proportions are optimal for the same wage-rental ratio at any scale of output.

15. We are grateful to James Tobin for discussions that clarified the analysis and led us to use this figure. 
Figure 1. Theoretical Model of Components of Unemployment

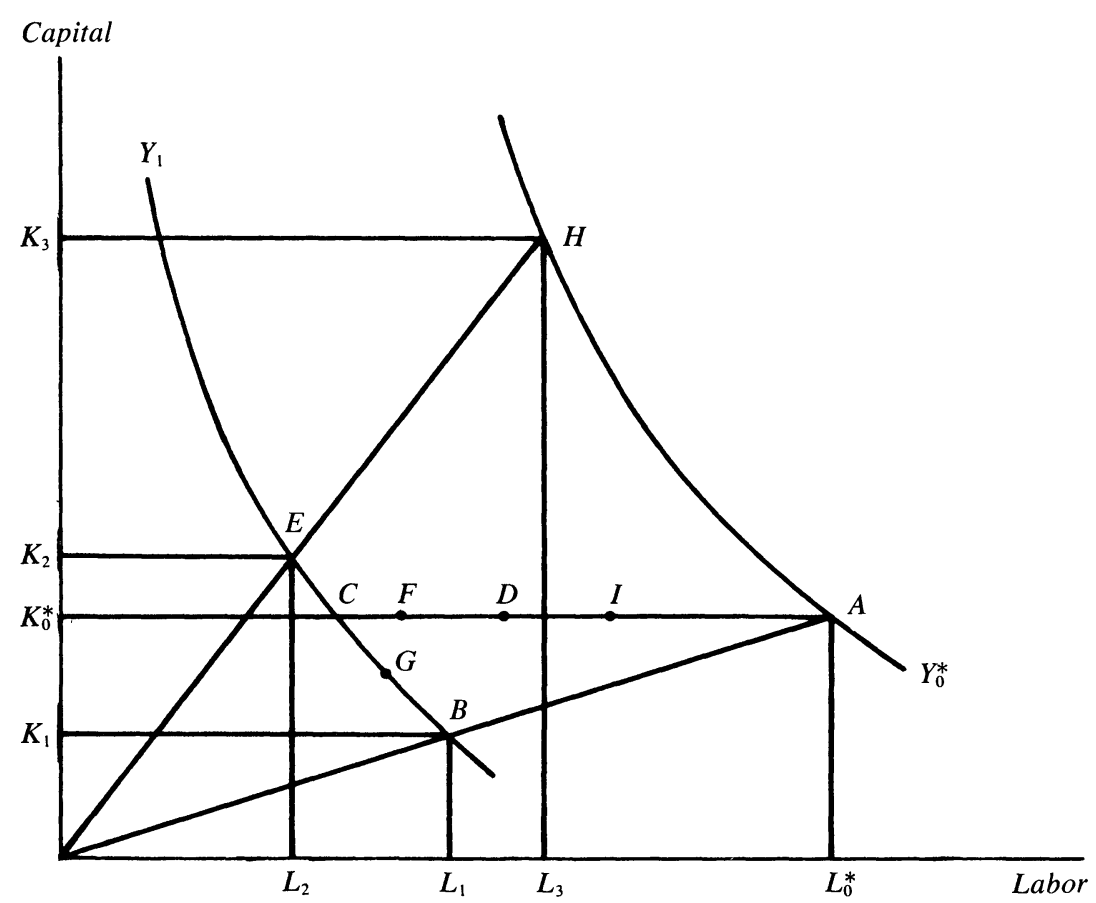

Suppose now that the economy is operating at point $E$ on the lower isoquant labeled $Y_{1}$ but at the higher wage-rental ratio, given by $(W / Q)_{1}=(W / P)_{1}[1 /(r+d)]$ and indicated by the higher ray through $E$. The new cost-minimizing inputs are related to output by the conditional factor demand functions:

$$
\begin{gathered}
L_{2}=[\alpha /(1-\alpha)]^{-\alpha}(W / Q)_{1}^{-\alpha} Y_{1}, \\
K_{2}=[\alpha /(1-\alpha)]^{1-\alpha}(W / Q)_{1}^{(1-\alpha)} Y_{1} .
\end{gathered}
$$

(We are momentarily neglecting lagged adjustments of factor inputs.) In this situation the observed wage gap is $(W / P)_{1}-(W / P)^{*}$ and unemployment equals $L_{0}^{*}-L_{2}$.

How responsive would employment be to a reduction of the real wage to $(W / P)^{*}$ ? The answer is crucial, since it determines the estimated amount of classical unemployment for the given wage gap. One approach 
would be to measure the employment change conditional on the level of capital stock at $E$, as in the short-run competitive model. With instantaneous labor adjustment and an unconstrained notional supply schedule, the short-run wage elasticity of labor demand is $-(1 / \alpha)$ and that of output supply is $-(1-\alpha) / \alpha$ under the Cobb-Douglas technology. Thus, given a reasonable value of 0.25 for $\alpha$, the implied labor elasticity would be -4 . This large elasticity reflects the substantial short-run supply response of competitive firms (with $\alpha=0.25$, a 1 percent reduction in the real wage increases the supply of output by 3 percent) and implies employment gaps several times the associated wage gaps. The crucial point is that these large responses would occur only if competitive firms were actually on their notional supply schedules in a regime of excess demand and that the wage gap would then be the sole cause of unemployment.

In contrast, with the demand constraint prevailing under imperfect competition and labor demand conditional on output, as in our behavioral interpretation of point $E$, a decline in the real wage from $(W / P)_{1}$ to $(W / P)^{*}$ would lead firms to raise employment to $L_{1}$, associated with point $B$ on the $Y_{1}$ isoquant. Thus, our estimate of classical unemployment is $L_{1}-L_{2}$; this is the amount that could be eliminated by removing the wage gap, given the level of aggregate demand. To eliminate the remaining unemployment, $L_{0}^{*}-L_{1}$, a higher level of aggregate demand is needed; hence, we refer to this component of unemployment as Keynesian.

From our specification of the labor demand function, equation 15, the wage elasticity of labor demand is $-\alpha$ rather than $-(1 / \alpha)$, or -0.25 rather than -4 . Classical unemployment from an excessive real wage is still possible and may even be dominant, but the coexistence of wage and demand components of unemployment is to be expected, and the division will depend on the particular configuration of real wages and effective demand. Despite the "small" elasticity, the real wage gap may be large enough to dominate excess unemployment occasionally or for several years at a time, as will be shown in the empirical results.

Several important observations need to be made about our decomposition of unemployment. First, the measure of each component is a conditional estimate. The classical component assesses the effect of a lower real wage, conditional on the observed level of demand; it does not allow for possible effects of a reduced real wage on aggregate 
demand. Similarly, the Keynesian component assesses the impact of an increase in aggregate demand, conditional on the real wage being at its full-employment equilibrium level; it does not allow for possible effects of an increase in aggregate demand on the real wage. By contrast, the classical component of unemployment, as usually defined, includes the effects of high real wages in reducing the quantity of output that firms are willing to supply and the related employment.

Second, the analysis does not identify the disturbances that depressed aggregate demand, raised the real wage, and thereby moved the economy from $A$ to $E$. The definitions of the classical and Keynesian components of unemployment refer to the state or existence of the real wage and demand gaps and not to the exogenous or endogenous forces creating the gaps. As one illustration, assume that an exogenous increase of money wages occurs at potential output without any adjustment of the price level (contrary to markup pricing behavior) or real aggregate demand. Classical unemployment would then occur as employment fell along the conditional labor demand schedule for potential output, or equivalently, employment would fall from $L_{0}^{*}$ to $L_{3}$ as the economy moved to point $H$ on the potential isoquant. Now assume instead that a nominal wage shock induces a less-than-proportional increase of prices in (at least) the short run (perhaps because invariant price markups are based on normal instead of current unit labor costs), so that the same rise in the real wage rate is accompanied by a higher price level. With an unchanged money supply, the induced decline of real balances would reduce effective demand and shift the labor demand function downward, adding a Keynesian component of unemployment to the classical one, or equivalently, moving the economy to, say, point $E$ on the lower isoquant where employment would be $L_{2}$ instead of $L_{3}$. Thus Keynesian unemployment can arise from an unaccommodated supply shock, owing to an induced change in effective demand. Conversely, an expansionary monetary or fiscal policy to reduce Keynesian unemployment may itself induce a decrease in the real wage and classical unemployment, provided nominal wages are incompletely indexed-or the reverse could occur if indexation is complete and the price markup varies strongly with demand. ${ }^{16}$

16. On this point, see Jeffrey Sachs, "Real Wages and Unemployment in the OECD Countries," BPEA, 1:1983, pp. 255-89, for an argument and supporting evidence that a demand expansion would probably raise real wage growth in Europe under the conditions prevailing at the time. 
Third, although it is true that at points $A, B, E$, and $H$ firms are employing cost-minimizing inputs for the given levels of demand and factor prices, only $A$ is a full macroeconomic equilibrium. Clearly the labor market is in a state of excess supply at the other points. But points $E$ and $H$ have an additional defect in that the realized rate of return on capital is smaller than the required rate. To see this latter point, recall that the realized rate of return is proportional to the output-capital ratio, since the marginal product of capital is $\alpha(Y / K)$. With our assumed technology, the output-capital ratio is monotonically related to the laborcapital ratio. Since the labor-capital ratio is smaller along the ray through $E$ and $H$ than the ratio along the ray through $B$ and $A$, the realized rate of return must also be smaller. ${ }^{17}$

In our imperfectly competitive framework in which firms are price setters, failure to realize the desired rate of return should lead producers to raise prices. If wages are imperfectly indexed to prices, the wage gap may be narrowed and the realized rate of return increased. However, the rise in the absolute price level may further depress the level of aggregate demand through Keynes and Pigou effects. While a complete macroeconomic model is obviously required to trace these repercussions of a wage gap, the less apparent point to note is that classical unemployment presents a more complicated problem of macroeconomic adjustment than does Keynesian unemployment. If the economy were at point $B$ experiencing only Keynesian unemployment, the required rate of return would be realized, since the labor-capital ratio is the same at $B$ and $A$. A demand stimulus that left the real wage unchanged could restore equilibrium in both the labor and capital markets. By contrast, if the economy were at $E$, a demand stimulus that left the real wage unchanged could reduce the excess supply of labor, but it would not correct the deficiency in the rate of return.

Fourth, the absence of adjustment lags in the foregoing exposition permits no distinction between short-run and long-run factor adjustments. However, adjustment lags are central features of our empirical models and substantially affect our estimates of classical and Keynesian

17. If there are separate prices for final output and capital goods, as in our empirical models, then the realized rate of return would be $R=\alpha(P / P I)(Y / \lambda K)-d$, where $P I$ is the capital goods price index, and $P$ is the price of final output. In this case, $R$ could remain unchanged at a lower output-capital ratio if the relative price of capital goods declined sufficiently. Investment tax credits or other subsidies could also be used to reduce the real rental rate while preserving the real rate of return at a higher capital-labor ratio. 
unemployment. To illustrate, consider once again figure 1. Suppose that the economy is operating under conditions of full-employment equilibrium at point $A$, producing the potential output $Y_{0}^{*}$ with the optimal inputs $L_{0}^{*}$ and $K_{0}^{*}$. Assume that a demand shock reduces output to $Y_{1}$ without affecting the real wage, so that the new desired inputs are given by $K_{1}$ and $L_{1}$ at point $B$. If the short run is defined as a period in which $K$ cannot change and $L$ fully adjusts, realized labor input would drop to point $C$, overshooting the long-run desired level, and Keynesian unemployment would equal $A-C$. In other words, full equilibrium would require a decrease in $K$ to move the economy to $B$, so that "long-run", Keynesian unemployment is overstated at point $C$. Since an equilibrium at $C$ would require a higher wage-rental ratio than at $B$, the horizontal distance between $B$ and $C$ is a kind of latent classical unemployment corresponding to a latent wage gap. If an actual wage gap accompanied the demand gap, moreover, so that full equilibrium were at $E$ with labor input $L_{2}$, the true classical unemployment component would be $L_{1}-L_{2}$ rather than the horizontal distance between $C$ and $L_{2}$, and classical unemployment would be understated by the same amount as Keynesian unemployment was overstated.

If one assumes, as we do, however, that adjustment costs induce firms to adjust their labor inputs only partially in a given year, Keynesian unemployment will not overshoot. Moreover, any existing classical component will always be observable. In the purely Keynesian case, for example, only part of the gap between $L_{0}^{*}$ and $L_{1}$ is closed and unemployment is equal to, say, $A-D$. Now assume that the real wage also increases when output drops. This could occur independently because of a wage or price shock, or it could be induced by the original fall in aggregate demand. In any event, the new desired inputs would differ and might be given by a point like $E$. If we again assume partial adjustment of the gap between the initial and the desired labor inputs, actual employment will be at point $F$, smaller than $D$. Total unemployment is $A-F$, of which the Keynesian component is $A-D$ and the classical share is $D-F$.

Note that owing to adjustment costs, the observed, measured quantities of $K$ and $L$ are not constrained to be on the production function in this system. However, the effective inputs of capital and labor services must be sufficient to produce the observed output. A given quantity of observed labor input, as measured for example by man-hours, may 
represent a greater or lesser amount of labor services or effective input when a man-hour is used more or less intensively, for example by altering the pace at which employees work or the number or duration of leisure breaks during a work shift. There is an additional degree of freedom for capital input, since the measured capital stock may be operated not only faster or slower per hour but also more or fewer hours per week. Thus, variations in the intensity of factor utilization (effective flow of factor services per measured unit of input) occur in the process of adjusting measured inputs toward the desired quantities. On the assumption that a firm increases its employment of a factor because it is using the current amount of the factor at greater than normal intensity, we posit that the intensities of utilization of $K$ and $L$ are proportional to the discrepancies between the observed and desired magnitudes. ${ }^{18}$ Hence, if measured inputs are at point $D$ while desired inputs are at point $B$, both capital and labor are underutilized because firms would like to reach a position in which they have less of both; if measured inputs are at point $F$, while desired inputs are at point $E$, labor is underutilized but capital is overutilized.

Thus far we have focused on labor input, but the capital stock will also adjust partially toward the new desired value given by $K_{1}$ or $K_{2}$. Some investment or disinvestment would occur on impact, but any incremental stock is assumed not to become operative until the end of the year, and similarly any discards are assumed to occur at the end of the year, so that actual $K$ is still fixed at $K_{0}^{*}$ insofar as the production function is concerned. Meanwhile, the accelerator effect of the output reduction will tend to decrease current investment whereas the substitution effect of the higher wage-rental ratio will tend to increase it. ${ }^{19}$ As drawn at point $E$, the substitution effect is larger and net investment is positive. If the increase in the wage-rental ratio were smaller than assumed in figure 1, however, so that $K_{2}$ and $L_{2}$ were at a point such as $G$ along a lower expansion path, the output effect would be dominant and investment would decrease on balance. In actual practice, an output shortfall is apt to occur because rising current output lags the growing potential level, instead of falling absolutely as was assumed for exposi-

18. Bert G. Hickman and Robert M. Coen, An Annual Growth Model of the U.S. Economy (Amsterdam: North-Holland, 1976), pp. 12-17.

19. The position of the lower isoquant must be consistent with the induced investment in the solution of the complete model. 
tional purposes in figure 1, so that both observed $K$ and observed $L$ will usually lag the equilibrium quantities and net investment will usually be positive.

Let us now trace through the effects of a real wage shock of the same size as before, so as to avoid the need for cluttering the diagram with another expansion path ray, but this time disturbing the original fullemployment equilibrium. If aggregate demand is unchanged, the new equilibrium will be at $H$ and the partial adjustment of $L$ would carry employment to a point such as $I$, generating classical unemployment of $A-I$. If the real wage increase were accompanied by an independent or induced change in aggregate demand and output, however, the new equilibrium would be along the expansion path through $H$ but on a lower isoquant. For graphical convenience only, it is assumed that the lower isoquant is again at $Y_{1}$ and the desired inputs are again given by point $E$. Total unemployment would then again be $A-F$, with a Keynesian share of $A-D$ and a classical component of $D-F$ (smaller than $A-I$ because the same proportional wage gap as on the lower isoquant between $E$ and $B$ is applied to a larger output between $H$ and $A$ ). The example is restrictive in that the wage and demand gaps would be equal only by accident when the wage gap was induced by a demand shock and the demand gap by a wage shock, but it serves conveniently to illustrate the proposition that the concepts of classical and Keynesian unemployment refer to economic states rather than to the shocks or responses that produced them.

\section{An Empirical Disequilibrium Growth Model}

Empirical implementation of our approach to factoring Keynesian and classical unemployment requires the specification of a dynamic structural model of the labor market and of the full-employment path of output and the real wage. For the United States, we rely on the relevant sectors of the Hickman-Coen Annual Growth Model, including its structure of interrelated factor demands, its disaggregated model of labor supply, and its model of the natural growth path of potential output. ${ }^{20}$

20. Robert M. Coen and Bert G. Hickman, "Constrained Joint Estimation of Factor Demand and Production Functions," Review of Economics and Statistics, vol. 52 (August 1970), pp. 287-300; Hickman and Coen, An Annual Growth Model; Coen and Hickman, “A Disaggregated Model of Labor Supply and Unemployment, 1951-2000," Working 
Although the U.S. model is a complete macroeconomic system combining Keynesian and neoclassical elements and allowing for departures from the full-employment growth path owing to deviations between effective demand and supply, the new European models are confined to the supply-side equations and treat aggregate demand and the wageprice level as exogenous variables for the purposes of the labor market simulations. Correspondingly, the empirical results for the United States are derived from stand-alone simulations of the labor sector of our annual growth model, with expected output and the expected real wage treated as predetermined variables in the labor demand function. The derivation is justifiable because the behavioral assumptions of the model conform to the imperfectly competitive paradigm of the preceding section. Firms set their prices as a markup over normal unit labor cost, with allowance in the markup for the costs of imported inputs and the current level of capacity utilization. For the given prices, output is determined by effective demand, which is disaggregated into three categories of investment, six of consumption, federal and state and local purchases, exports, and imports. Nominal wages are determined by an expectations-augmented Phillips curve. Since this paper is not concerned with output determination, the inflation-unemployment trade-off, or the absolute price level, none of these sectors is operational in the subsequent analysis.

The following sections describe the general forms of the empirical equations of the U.S. model and note differences between the U.S. equations and those of the European nations. Estimates of key parameters and elasticities are also reported. The data are briefly described in footnotes to the tables and text. A full listing of the estimated equations and their statistical properties is available from the authors.

\section{The Labor Market}

\section{LABOR SUPPLY}

The U.S. model contains labor force participation equations for sixteen age-sex groups, of the form

Paper 80-15 (Institute of Applied Systems Analysis, Laxenburg, Austria, January 1980); Coen and Hickman, "The Natural Growth Path of Potential Output," Working Paper 80132 (Institute of Applied Systems Analysis, Laxenburg, Austria, August 1980). 


$$
\begin{aligned}
L_{i t}= & N N I_{i t}\left[a_{1, i}+a_{2, i}(E / N N)_{t}+a_{3, i}(L A / N N I)_{t}\right. \\
& \left.+a_{4, i}(W A T / P C)_{t}+a_{5, i} A H_{t}+a_{6, i} t+a_{7, i} N M R A T_{t}\right],
\end{aligned}
$$

where $L_{i}$ is the labor force and $N N I_{i}$ the population in the $i$ th group, $E$ is aggregate employment, $N N I$ is the noninstitutional population sixteen years of age or older, $L A$ is the number of persons in the armed forces, $W A T$ is the after-tax wage rate, $P C$ is the implicit deflator for consumer goods, $A H$ is aggregate average hours of work, $t$ is a time index, and $N M R A T$ is the ratio of males aged sixteen to thirty-four to those aged thirty-five to sixty-four. The ratio $E / N N I$ captures the discouraged worker effect, whereas NMRAT is included in the female participation equations only, in conformity with the hypothesis that increases in this ratio affect the participation rates of younger women positively and of older women negatively. ${ }^{21}$

The single equation for average hours in the United States takes the form

$$
A H_{t}=\exp \left[b_{1}+b_{2} \log (W A T / P C)_{t}+b_{3} \log U_{t}+b_{4} \log L W_{t}\right],
$$

where $A H$ is average hours per year, $U$ is the unemployment rate, and $L W$ is the proportion of women aged twenty and over. Workers' desired hours are assumed to depend on the wage rate, but cyclical variations in labor demand, proxied here by the unemployment rate, may affect actual hours. Average hours may also vary inversely with the proportion of women in the labor force, since women are more likely than men to engage in part-time work.

The labor supply model is completed by summing over the relevant age-sex participation equations to obtain $L$ and $L W$.

The same general specification of labor supply is used for the European countries, except that the demographic disaggregation differs, the armed forces variable is dropped from equation 17 , and the cyclical unemployment variable was found to be insignificant in the hours equations for Austria and Germany.

\section{LABOR DEMAND}

The demands for labor and capital are interrelated in the model, since they are jointly derived on the assumption that firms minimize production

21. Richard A. Easterlin, What Will 1984 Be Like? Socioeconomic Implications of Recent Twists in Age Structure (Columbia University Press for the National Bureau of Economic Research, 1978). 
costs subject to a long-run or planning Cobb-Douglas production function with constant returns to scale:

$$
X N R_{t}^{*}=A e^{\beta t}\left(K_{t}^{*}\right)^{\alpha}\left(M H_{t}^{*}\right)^{1-\alpha}, \quad A, \alpha, \beta>0,
$$

where $X N R^{*}$ is expected output, $K^{*}$ is the desired stock of fixed capital, ${ }^{22}$ $M H^{*}$ is desired man-hours, and $\beta$ is the rate of Hicks-neutral technical progress.

Minimizing production cost subject to equation 19 gives the long-run factor demand functions:

$$
\begin{gathered}
M H_{t}^{*}=[\alpha /(1-\alpha)]^{-\alpha} A^{-1}\left[\left(W^{*} / Q^{*}\right)_{t}\right]^{-\alpha} X N R_{t}^{*} e^{-\beta t} \text { and } \\
K_{t}^{*}=[\alpha /(1-\alpha)]^{1-\alpha} A^{-1}\left[\left(W^{*} / Q^{*}\right)_{t}\right]^{(1-\alpha)} X N R_{t}^{*} e^{-\beta t},
\end{gathered}
$$

where $Q^{*}$ is the expected implicit rental price of capital and $W^{*}$ is the expected nominal before-tax wage rate. The implicit rental price is defined by $Q \equiv P I(r+d) T$, where $P I$ is the investment price deflator, $r$ is the after-tax rate of return, $d$ is the depreciation rate, and $T$ symbolizes the tax treatment of investment expenditure. ${ }^{23}$

Adjustment costs prevent firms from accommodating immediately to variations in the desired inputs. These adjustment costs include external purchase costs and internal installation costs for capital goods and hiring, training, and layoff costs for labor. They are represented implicitly by exponential partial adjustment processes:

$$
M H_{t} / M H_{t-1}=M H_{t}^{*} /\left(M H_{t-1}\right)^{f}, \quad 0<f \leq 1,
$$

22. Measured by nonresidential fixed capital for the United States and total fixed capital for the European countries. See footnote a, table 15, for detailed sources.

23. For all countries, the capital goods price index is the implicit deflator for gross investment; the economic depreciation rate is the same as that used in constructing estimates of net capital; and the discount rate is 6 percent per annum. Tax parameters required in the measurement of the rental cost are based on tax legislation for the United States. For Germany, these parameters are adapted from Patrick Artus, Pierre-Alain Muet, Peter Palinkas, and Peter Pauly, "Tax Incentives, Monetary Policy, and Investment in France and Germany," in G. de Menil and U. Westphal, eds., Stabilization Policy in France and Germany (Amsterdam: Elsevier Science Publishers, 1984); Mervyn A. King and Don Fullerton, eds., The Taxation of Income from Capital: A Comparative Study of the United States, the United Kingdom, Sweden, and West Germany (University of Chicago Press, 1984). For Austria, they are adapted from a study by Karl Aiginger, "Die industrieinvestionen in Oesterreich, 1955-1980," Industrieinvestionen in Oesterreich, Band 7/8 (Vienna: Oesterreich Investitionskredit Aktiengesellschaft), pp. 7-152, and subsequent updates to that study supplied by the author. Under British tax laws, much of investment could be expensed rather than depreciated. For simplicity, we assume complete expensing, in which case tax parameters do not appear in the rental cost. 


$$
K_{t} / K_{t-1}=K_{t}^{*} /\left(K_{t-1}\right)^{g}, \quad 0<g \leq 1,
$$

where $f$ and $g$ are the adjustment speeds for labor and capital.

Combining the desired input and adjustment hypotheses yields the short-term or disequilibrium demand functions:

$$
\begin{aligned}
& M H_{t}=\left\{[\alpha /(1-\alpha)]^{-\alpha} A^{-1}\left[\left(W^{*} / Q^{*}\right)_{t}\right]^{-\alpha} X N R_{t}^{*} e^{-\beta t}\right\} f M H_{t-1}^{1-f}, \\
& K_{t}=\left\{[\alpha /(1-\alpha)]^{1-\alpha} A^{-1}\left[\left(W^{*} / Q^{*}\right)_{t}\right]^{1-\alpha} X N R_{t}^{*} e^{-\beta t}\right\}^{g} K_{t-1}^{1-g} .
\end{aligned}
$$

Because man-hours and capital adjust with lags to changes in the desired quantities, the observed inputs may be over- or underutilized in current production, and hence the short-run production function in the model allows for variations in the intensity of use of measured capital and labor inputs. The rates of factor utilization are determined endogenously by the factor adjustment processes. ${ }^{24}$ The procyclical behavior of measured labor productivity is also explained by the lagged adjustment of man-hours to changes in output.

Joint estimation of the short-run demand functions yields estimated values of the adjustment speeds $f$ and $g$ and of the structural parameters of the production function and long-run factor demand functions. Expectations of wages, prices, and output are determined autoregressively, except for the expected wage in the U.S. model, which is determined from the wage equation, assuming that agents know the Phillips curve and estimate $W$ on the basis of the unemployment gap observed in the previous period. Significant breaks in the rate of technical progress, or growth rate of total factor productivity, are found in the estimates for all countries after the first oil shock and account for much of the slowdown of labor productivity and potential output, as will be seen below.

\section{Determination of Potential Output}

A short-run disequilibrium is determined each period in the simultaneous solution of the labor market equations. Firms are not in long-run equilibrium because adjustment costs keep them off their planning production function. Neither is there continuous market clearing, since

24. Hickman and Coen, An Annual Growth Model; Coen and Hickman, "The Natural Growth Path." 
excess unemployment may exist at the prevailing real wage, either because of deficient aggregate demand or a gap between the fullemployment and market wage. As explained earlier, to measure the extent of classical and Keynesian unemployment, it is first necessary to determine potential output and the full-employment real wage. Our empirical estimates of these variables are conceptually the same as those derived earlier for a simplified static model, but they also allow for population growth and the endogeneity of labor supply, for the distinction between employment and man-hours, for the dynamics of factor adjustments, and for technical progress.

\section{THE NATURAL UNEMPLOYMENT RATE}

The first step is to specify the natural unemployment rate in order to estimate the full-employment labor supply. We follow Michael Wachter in the method of accounting for the effects of changes in the age-sex composition of the labor force on structural unemployment. ${ }^{25}$ In the United States, the demographic shift toward younger workers from the mid-fifties to the mid-seventies increased the importance of age groups with persistently high unemployment rates. Moreover, minimum wage legislation may have prevented adjustments in demand favoring untrained and lower-skilled young workers, and unemployment insurance reduced the cost of unemployment so that structural and frictional unemployment may have risen among secondary workers, further increasing their already high unemployment rates. Thus some increase in the aggregate unemployment rate consistent with a given degree of labor market tightness and nominal wage pressures is to be expected.

The basic assumption in estimating the natural rate is that prime-age male workers were largely unaffected by these labor market developments, so that their unemployment rate in a benchmark year can be interpreted as a specific full-employment unemployment rate that does not change over time and therefore can be used to isolate that portion of the change in unemployment rates of the other age-sex groups that is structural rather than cyclical.

25. Michael L. Wachter, "The Changing Cyclical Responsiveness of Wage Inflation," BPEA, 1:1976, pp. 115-59. 
The natural unemployment rate for the United States is calculated as a weighted average of the natural rates for the sixteen age-sex groups:

$$
U F_{t} \equiv \sum_{i=1}^{16} U F_{i t}\left(L F_{i t} / L F_{t}\right)
$$

where $U F_{i}$ is the full-employment unemployment rate and $L F_{i}$ the fullemployment labor force in the $i$ th age-sex group.

The $U F_{i t}$ are based on the following regression:

$$
U_{i t}=\exp \left[c_{1}+c_{2} \log U_{p t}+c_{3} \log \left(N N I_{i t} / N N I_{t}\right)\right],
$$

where $U_{i}$ is the actual unemployment rate in the $i$ th group, $U_{p}$ is the unemployment rate in the prime-age male group (forty-five to fifty-four in the United States) and the other variables are as defined earlier. Thus cyclical variations in the age-sex specific unemployment rates are related to cyclical variations in $U_{p}$, whereas structural shifts in the $U_{i}$ over time are related to the share of the $i$ th group in the total population. The fullemployment unemployment rate for prime-age males, $U F_{p t}$, is held constant at its 1956 level (3.0 percent in the United States), and the other $U F_{i t}$ are estimated by setting $U_{p t}=3.0$ in equation 27 and calculating the value of the right-hand side.

Natural unemployment rates for the other countries are similarly constructed. The prime-age male group in each country is identified as the group with both a low mean unemployment rate and small variance relative to the mean-forty- to forty-nine-year-olds in Austria, fortyfive- to fifty-four-year-olds in Germany, and thirty-five- to forty-fouryear-olds in the United Kingdom. The natural rate for the prime group is assumed to be constant at the 1965-69 average value of the group's actual unemployment rate-1.3 percent for the Austrian group, 0.9 for the German group, and 1.5 for the U.K. group.

It is important to emphasize that $U F$ is not a nonaccelerating inflation rate of unemployment (NAIRU), since it is not calculated from a Phillips curve by imposing the nonacceleration constraint. It does take account of changes over time in factors affecting structural and frictional unemployment and the related changes in labor market tightness, but it does not impose the assumption of a vertical long-run Phillips curve.

The natural unemployment rate equations, together with the participation equations, average hours equation, and identities defining labor 
market aggregates, compose a labor supply system that jointly determines full-employment values of the labor force, employment, unemployment, and average hours, conditional on the real after-tax consumption wage and demographic variables. The product of employment and average hours gives the full-employment supply of man-hours, denoted $M H F$.

\section{THE NATURAL GROWTH PATH}

We define potential gross national product as that output that would be realized each year if the markets for labor and capital were continuously cleared at the natural rate of unemployment-that is, as the output along an equilibrium growth path. ${ }^{26} \mathrm{~A}$ key characteristic of this concept is that potential output is unaffected by deviations of actual output, factor inputs, and real factor prices from their full-employment values. Departures from the natural path imply disequilibrium in the factor markets, as the quantities of capital and labor deviate from their fullemployment levels, but these temporary deviations do not affect potential output in subsequent periods, since they can be offset by future changes in investment and employment.

Along the natural growth path of potential output, both labor and capital are fully employed. Making use first of the labor market condition, we define potential output as the level of output that would equate labor supply and demand at the natural rate of unemployment and fullemployment wage rate. Since the labor demand function, equation 24 , relates man-hours to output and relative factor prices, an expression may be derived for potential output, conditional on the wage-rental ratio, by substituting $M H F$ for $M H$ and solving the equation for output:

$$
X N R P_{t}=A[\alpha /(1-\alpha)]^{\alpha}\left[\left(W^{*} / Q^{*}\right)_{t}\right]^{\alpha} e^{\beta t} M H F_{t}^{1 / f} M H F_{t-1}^{-(1-f) / f},
$$

where $X N R P$ is potential output. Since full employment would prevail each period along the natural growth path, note that $X N R P$ depends on $M H F$ in the current and preceding year, and hence on all previous years since the path was established, irrespective of whether the economy actually operated at full employment in the preceding year.

26. Coen and Hickman, "The Natural Growth Path." 
It remains to determine $W^{*} / Q^{*}=\left(W^{*} / P I^{*}\right)[(d+r) T]^{-1}$. To do so, we assume that the real product wage grows at the same rate as potential labor productivity along the natural path: ${ }^{27}$

$$
(W / P)_{t} /(W / P)_{t-1}=(X N R P / M H F)_{t} /(X N R P / M H F)_{t-1} .
$$

The real wage in the labor demand function is in terms of capital goods prices and that in the labor supply equations in terms of consumer prices, but the differential trend of consumer and capital goods prices is small enough that we ignore it for present purposes, setting $(W / P)=(W / P I)$ in equation 29 and correcting $(W / P C)$ for taxes to derive $(W A T / P C)$ in equations 17 and 18.

Finally, with real wage expectations assumed to be realized along the natural growth path,

$$
\left(W^{*} / Q^{*}\right)_{t} \equiv(W / P I)_{t}[(d+r) T]_{t}^{-1},
$$

where the last term is an autonomous component of $\left(W^{*} / Q^{*}\right)$, since $d$ and $r$ are exogenous and only changes in $T$ that are unanticipated and permanent are assumed to affect the equilibrium capital-labor ratio. (The value of $r$ is constant at 6 percent and may be viewed as a required rate of return on fixed investment. ${ }^{28}$ Hence the equilibrium wage-rental ratio increases at the same rate as labor productivity and the real wage along the natural path.

27. This assumption is not only observationally realistic but also consistent with the overall structure of the model. Nominal wages and prices are endogenous in the complete model, but prices are related to unit labor costs with a constant long-term markup, implying constant factor shares in long-run equilibrium and equality of the growth rates of the real wage and labor productivity.

28. In our earlier research on the U.S. economy [Coen and Hickman, "Testing Factor Demands for Monetary Influences and Technical Change in the Postwar Economy," Research Memorandum 241 (Center for Research in Economic Growth, Stanford University, May 1980)], we tested many alternative measures of $r$ involving financial market variables: the after-tax long-term interest rate in nominal units and adjusted for expected inflation; the corresponding nominal and real after-tax short-term interest rates; and weighted averages of after-tax bond yields and two different measures of the return on equities, again with and without adjustment for expected inflation. None of these constructs performed as well in the estimation of the factor demand equations as the alternative of an assumed constant rate of discount of 7 percent (subsequently reduced to 6 percent on the basis of direct evidence on real returns to equity).

Our new estimates for Austria, Germany, and the United Kingdom also incorporate a constant discount rate of 6 percent. This assumption was again tested against the market alternatives of the nominal and real after-tax bond yields and found to lead to superior estimates of the demands for capital and labor. 
All the ingredients are now in place to determine the full-employment path. Rewriting equation 28 in productivity form as

$$
(X N R P / M H F)_{t}=B\left[\left(W^{*} / Q^{*}\right)_{t}\right]^{\alpha} e^{\beta t}\left(M H F_{t} / M H F_{t-1}\right)^{(1-f) / f},
$$

where $B=A[(1-\alpha) / \alpha]^{-\alpha}$, and using equations $17-18,26-27$, and 29-31, and related identities, one can solve simultaneously for the fullemployment values of labor productivity, output, labor force, employment, unemployment, hours of work, and the real wage and wage-rental ratio along the natural growth path, for exogenous values of the demographic and policy variables (population, armed forces, government employment, and tax parameters). The resulting estimates of the fullemployment wage rate, labor force, employment, and hours are used in the subsequent analysis of Keynesian and classical unemployment.

Capital as well as labor must be fully employed along the natural growth path. In the standard neoclassical model, a constant fraction of output is saved and automatically invested; the growth path depends on the saving rate, and the real wage and return on capital adjust to maintain full employment of both factors. In contrast, our annual growth model includes an explicit investment demand function, equation 25 , which determines actual business fixed investment, and saving need not equal investment ex ante. Our full-employment equilibrium growth path is based not on a given saving rate, but on a given required rate of return on capital..$^{29}$ Equation 25 may therefore be used to determine the path of potential capital, by setting current and lagged capital stock and current output equal to their full-employment values $K F_{t}, K F_{t-1}$, and $X N R P_{t}$. With the revised equation 25 and the identity relating gross investment and capital stock,

$$
I F_{t} \equiv K F_{t}-(1-d) K F_{t-1},
$$

added to the earlier equation system, the net and gross fixed investment required to sustain the natural growth path are fully determinate. A greater flow of saving could not be profitably absorbed in fixed capital formation under the given investment conditions, and a smaller flow would be inadequate to attain the required rate of capital deepening to equilibrate the capital-labor and wage-rental ratios.

29. See note 28 . 


\section{Decomposing Classical and Keynesian Unemployment}

Our initial exposition of the impact of high real wages and deficient effective demand on unemployment utilized an isoquant diagram to focus on firms' labor and capital input decisions. To allow for an endogenous labor supply and employment dynamics in the decomposition of unemployment, it is more convenient to work with labor supply and demand functions, comparing the actual schedules to their full-employment counterparts. For simplicity, induced variations in average hours are neglected in the theoretical exposition, although they are taken into account in the empirical estimates. Similarly, we abstract from expectational errors in the theoretical exposition by assuming perfect foresight on the real wage. ${ }^{30}$ Finally, some complications associated with the carryover effects of lagged disequilibrium in the labor market are postponed for later discussion.

\section{LABOR SUPPLY AND DEMAND}

The conceptual framework is illustrated in figure 2, in which the real wage rate is measured vertically and the quantity of employment horizontally. The short-run labor demand function is labeled $L D$, and its position depends on the quantity of current output and on lagged employment and other variables as discussed above. At the current real wage and output levels, $E$ persons are employed. The labor supply function, $L$, is shown as inelastic to the real wage, in view of the small magnitudes of the estimated elasticities in the various countries discussed below. Its position depends on the level and age-sex distribution of the population, and also on the level of $E$, owing to the discouraged-worker effect on labor force participation. The number of unemployed workers is given by $U N=(L-E)$.

The full-employment labor force is $L F$, and $E F$ is the corresponding "full-employment" volume of employment, equal to $(L F-U N F)$, where $U N F$ is the number of persons who would be unemployed at the

30. The empirical measures are based on the expected real wage. It was shown in Hickman, "Real Wages, Aggregate Demand, and Unemployment," that expectational errors are normally unimportant determinants of the magnitude of classical unemployment in the United States, and the same finding applies for the other countries in our sample. 
Figure 2. Labor Demand and Supply, Actual and Full-Employment

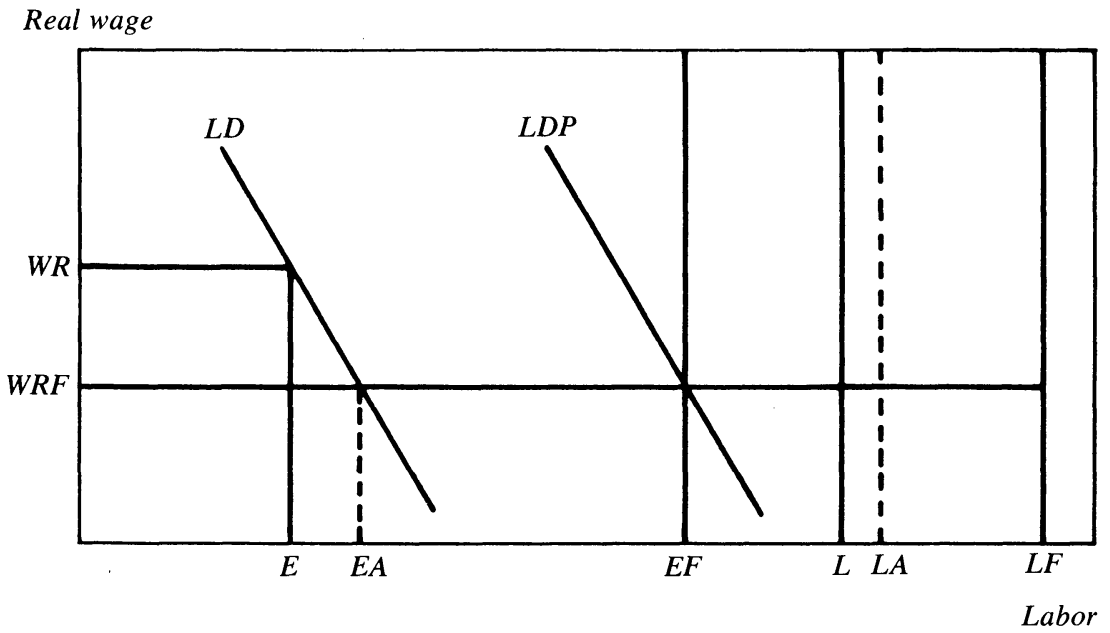

natural rate of unemployment $U F$. The labor demand function at potential output is $L D P$, and $W R F$ is the real wage rate that would clear the labor market, except for natural unemployment, if output were at its potential level. As discussed above, all these full-employment functions and magnitudes are simultaneously determined in the solution for the natural growth path.

Suppose now that the real wage were reduced to $W R F$ while aggregate demand and output remained unchanged. The level of employment under this hypothetical experiment would be $E A$. Thus of the total shortfall of employment $(E F-E)$, an amount $(E A-E)$ is attributable to the wage gap $(W R-W R F)$. The remainder $(E F-E A)$ stems from deficient effective demand for output. The employment shortfall may therefore be decomposed into its wage and demand components:

$$
E F-E=(E A-E)+(E F-E A) .
$$

At the prevailing wage, excess unemployment exists amounting to $U N-U N F$. The excess may be decomposed in two ways. First, since

$$
U N-U N F=(L-E)-(L F-E F)=(E F-E)-(L F-L),
$$

the excess is smaller than the employment shortfall by the amount of "hidden" unemployment $(L F-L)$. The hidden unemployment is due to the induced withdrawal of potential workers from the labor force 
because of a perceived lack of job opportunities at the current employment level.

Second, the excess unemployment may also be factored into a wage component equal to $(U N-U N A)$ and a demand component given by $(U N A-U N F)$, corresponding to the associated employment shortfalls:

$$
U N-U N F=(U N-U N A)+(U N A-U N F) .
$$

The wage component of equation 35 is equal to

$$
U N-U N A=(L-E)-(L A-E A)=(E A-E)-(L A-L) .
$$

Under the hypothetical wage reduction, the increase of employment to $E A$ would induce an increase of the labor force to $L A$. Thus unemployment would fall less than employment rose, owing to the induced reduction of hidden unemployment. ${ }^{31}$

The demand component of equation 35 equals

$$
\begin{aligned}
U N A-U N F & =(L A-E A)-(L F-E F) \\
& =(E F-E A)-(L F-L A) .
\end{aligned}
$$

Thus the demand component of total excess unemployment consists of the residual employment shortfall less the residual volume of hidden unemployment. The smaller employment shortfall at the reduced real wage would be partly offset by the induced reduction of hidden unemployment.

This demand component could exist even if the real wage were at the full-employment level. Since it reflects deficient demand in the product market, it represents the Keynesian component of excess unemployment. Correspondingly, the wage component measures the extent of classical unemployment due to an excessive real wage rate.

31. This statement neglects the dependence of labor supply on the real wage as well as on employment. To the extent that changes in the real wage affect the size of the labor force, the expression $L A-L$ does not correspond to the usual notion of hidden unemployment; rather, it measures the increase in labor force induced by the rise in employment plus the increase or decrease directly induced by the decline in the real wage. For the countries in our study except Austria, the estimated elasticities, reported below, of labor force with respect to real wages are negative (income effects dominate substitution effects), so that for these countries $L A-L$ will exceed hidden unemployment, while for Austria it will be smaller than hidden unemployment. This qualification is not important quantitatively, however, because the elasticities are all rather small in absolute value. 
Figure 3. Carryover Component of Employment Shortfall

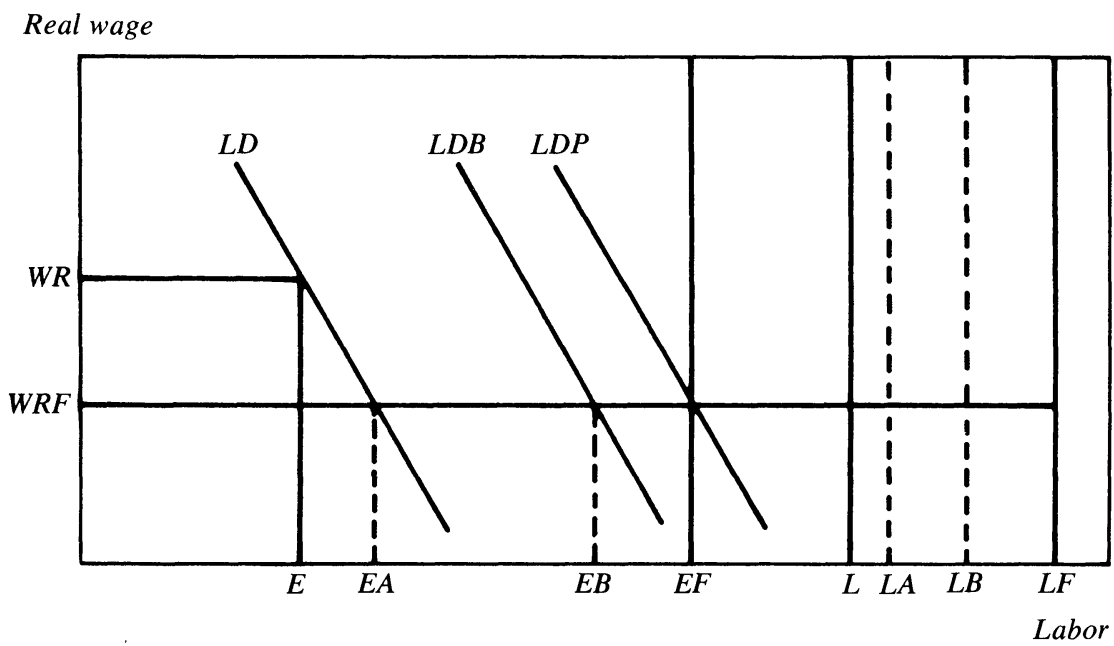

EMPLOYMENT DYNAMICS AND CARRYOVER UNEMPLOYMENT

It might be thought that the demand component of the employment shortfall $(E F-E A)$ would necessarily be zero when actual and potential output were equal. This is not generally true, however, since equality of actual and potential output does not imply that the actual demand function for labor $L D$ coincides with the full-employment demand schedule $L D P$. Both schedules depend on lagged employment, but this is measured by $E F(-1)$ instead of $E(-1)$ in the case of $L D P$, since the natural growth path is defined for a condition of continuous full employment. Thus $L D$ would coincide with $L D P$ only if actual and potential output were equal and labor were fully employed in the preceding period.

Figure 3 illustrates the situation when a shortfall of actual output in this period follows upon excess unemployment in the preceding period, as would occur, for example, if output and employment fell below their potential levels in period $(t-1)$ and output recovered only partially in period $(t)$.

The actual and full-employment demand and supply schedules and the associated quantities are the same as before. The new schedule $L D B$ is hypothetical and shows the demand for labor that would exist if actual output were at the potential level, given the actual employment of the 
preceding period. The distance $(E F-E B)$ measures the carryover component of the total employment shortfall $(E F-E)$. It is the residual shortfall that would persist even if actual output and the real wage were both at their potential levels in period $(t)$, owing to the drag exerted by the employment shortfall $(E F-E)$ in $(t-1)$.

If carryover unemployment is recognized as a separate category, the employment shortfall may be decomposed into three elements:

$$
E F-E=(E A-E)+(E B-E A)+(E F-E B) .
$$

In this formulation, $(E B-E A)$ measures the employment shortfall due to a current potential output gap, just as $(E A-E)$ measures that due to a current wage gap.

In the illustrative example, the potential output gap is negative $(Y<Y P)$ and the wage gap positive $(W R>W R F)$, but the gaps may go either way in principle, and the potential output gaps are frequently positive in the empirical estimates. The corresponding breakdown of excess unemployment is given by

$$
\begin{aligned}
U N-U N F= & (U N-U N A)+(U N A-U N B) \\
& +(U N B-U N F),
\end{aligned}
$$

where $U N B=L B-E B$, and the other terms were defined earlier.

These threefold decompositions are interesting and meaningful, and empirical estimates based on equations 38 and 39 were presented for the United States by Hickman. ${ }^{32}$ The twofold breakdowns given by equations 33 and 35 are preferred, however, on the ground that the contribution of deficient aggregate demand to excess unemployment should be measured by the gap between actual output and full-employment output, defined as that output that would be required to achieve full employment of labor if the real wage were at the full-employment level, rather than by the gap between actual and potential output. On this interpretation, the volume of Keynesian unemployment includes the carryover component and is measured by $(U N A-U N F)$ rather than $(U N A-U N B)$.

A precise measure of the level of full-employment output $(X N R F)$ is given by

$$
X N R F_{t}=A[\alpha /(1-\alpha)]^{\alpha} e^{\beta t}\left[(W F / Q F)_{t}\right]^{\alpha} M H F_{t}^{1 / f} M H_{t-1}^{-(1-f) / f},
$$

32. Hickman, "Real Wages, Aggregate Demand, and Unemployment." 
which differs from the expression for potential output in equation 28 only by having lagged man-hours substituted for lagged full-employment man-hours in the last term. Thus $X N R F$ is that output level that would induce firms to hire the full-employment labor supply at the fullemployment wage rate, given the level of actual man-hours in the preceding period. It may exceed or fall short of potential output according to whether actual man-hours were lower or higher than full-employment man-hours in the preceding period. ${ }^{33}$

Note that $X N R F$ is closer to most concepts of potential output than is $X N R P$, since the former takes as an initial condition each period the actual state of the labor (and capital) market in the previous period. If $X N R F$ were used to define potential output instead of $X N R P$, no carryover term would be identifiable as an element of the demand component $E F-E A$.

\section{Measuring the Wage and Employment Gaps}

Real wages play a critical role in our analysis of the influence of wage gaps on unemployment and productivity growth. The real after-tax consumption wage affects labor force participation and average working hours, whereas the real wage in terms of capital goods prices is the key variable determining the capital-labor ratio. The solution for the natural growth path of potential output constrains both real wage rates to increase at the same geometric rate as potential man-hour productivity, before the potential consumption wage is corrected for taxes.

An exogenous price shock to the potential investment wage cannot be directly captured in this framework, however. In the case of the first oil shock, for example, the unanticipated explosion of import prices $(P M)$ raised the prices of investment goods $(P I)$ sharply relative to money wages $(W)$ in the United States, leading to an abrupt drop in the ratio of the real wage (WPI) to labor productivity $(P R O D)$ that persisted into the early eighties, as shown in figure 4 . For given values of the other

33. A similar distinction between full-employment output and potential output is discussed in Hickman and Coen, "An Annual Growth Model," pp. 17-19, but without relating their definitions to the concept of the natural growth path. The latter concept dates from Coen and Hickman, "The Natural Growth Path." 
Figure 4. Ratio of Real Wages to Productivity, United States, United Kingdom, Germany, and Austria, 1966-84a

Ratio of real wages to productivity

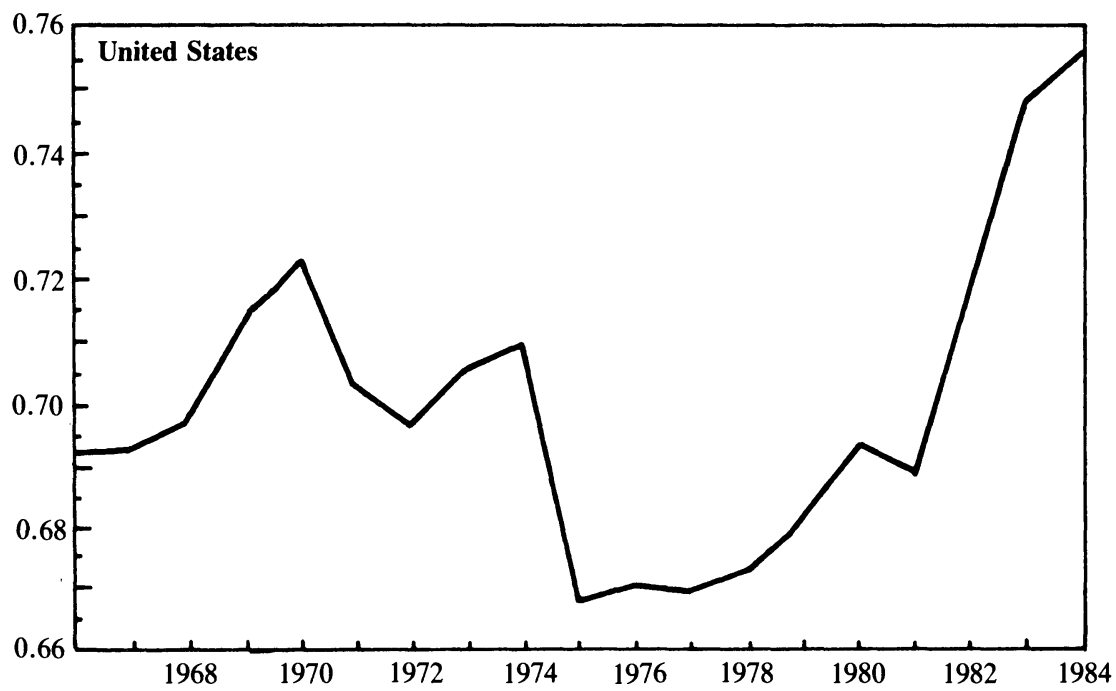

Ratio of real wages to productivity

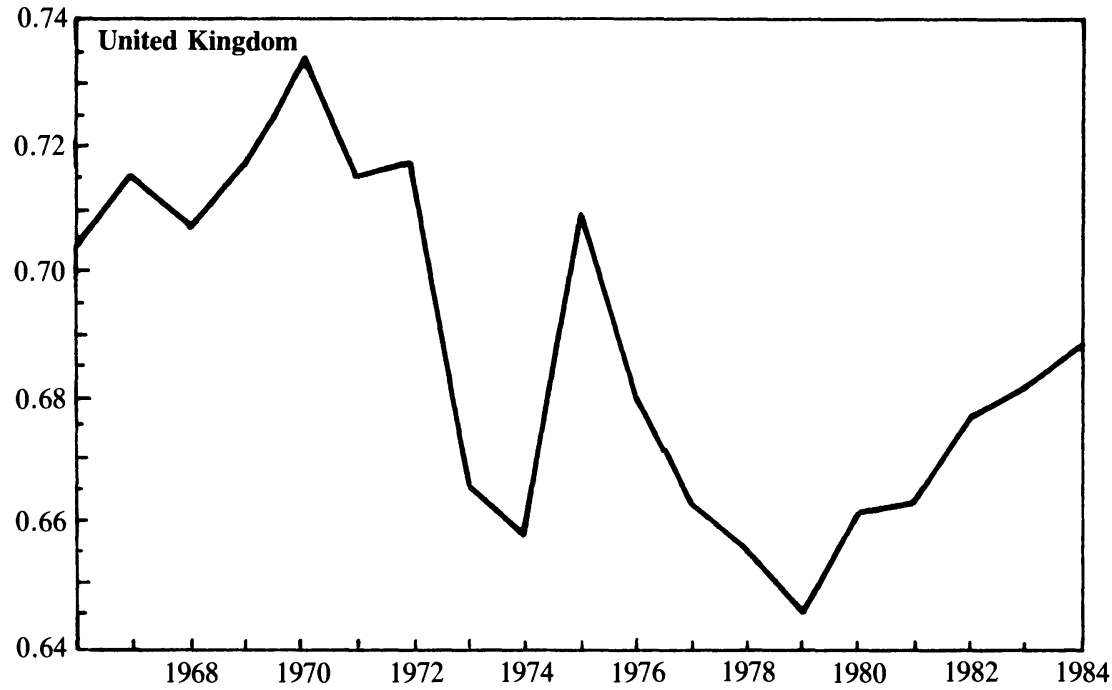

Source: Authors' calculations based on data from the following sources: for the United States, U.S. Department of Labor, Bureau of Labor Statistics; for Austria, Austrian Institute for Economic Research; for Germany and the United Kingdom, Organization for Economic Cooperation and Development, Labor Force Statistics, various issues, and additional unpublished data from the OECD. 
Ratio of real wages to productivity

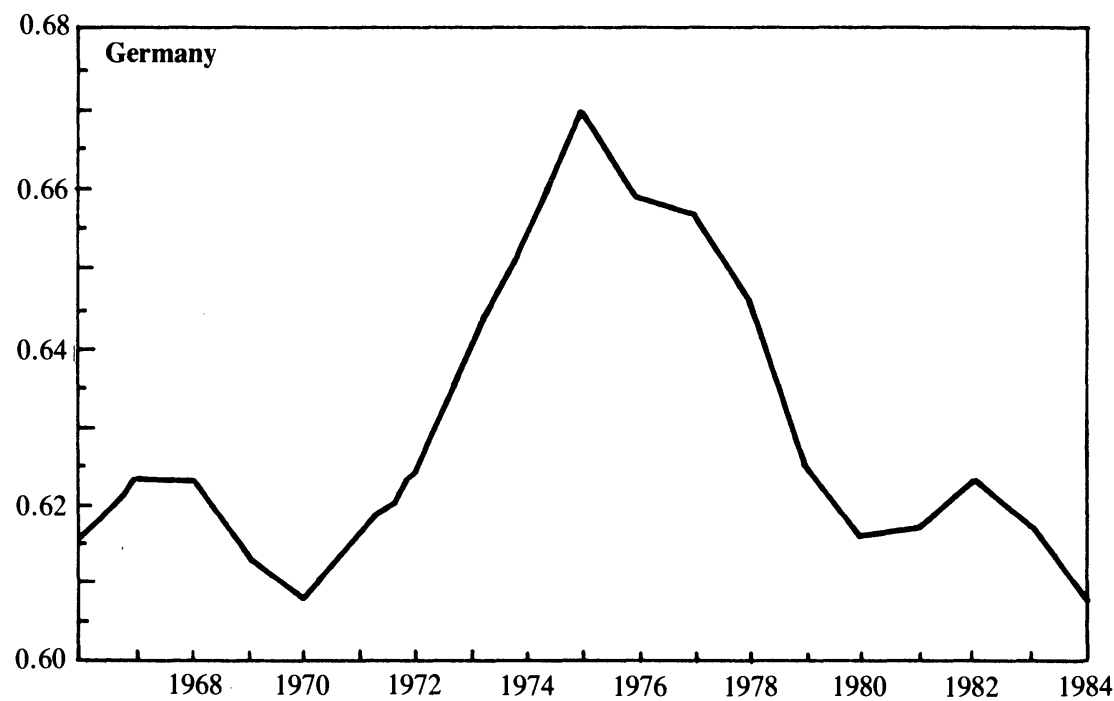

Ratio of real wages to productivity

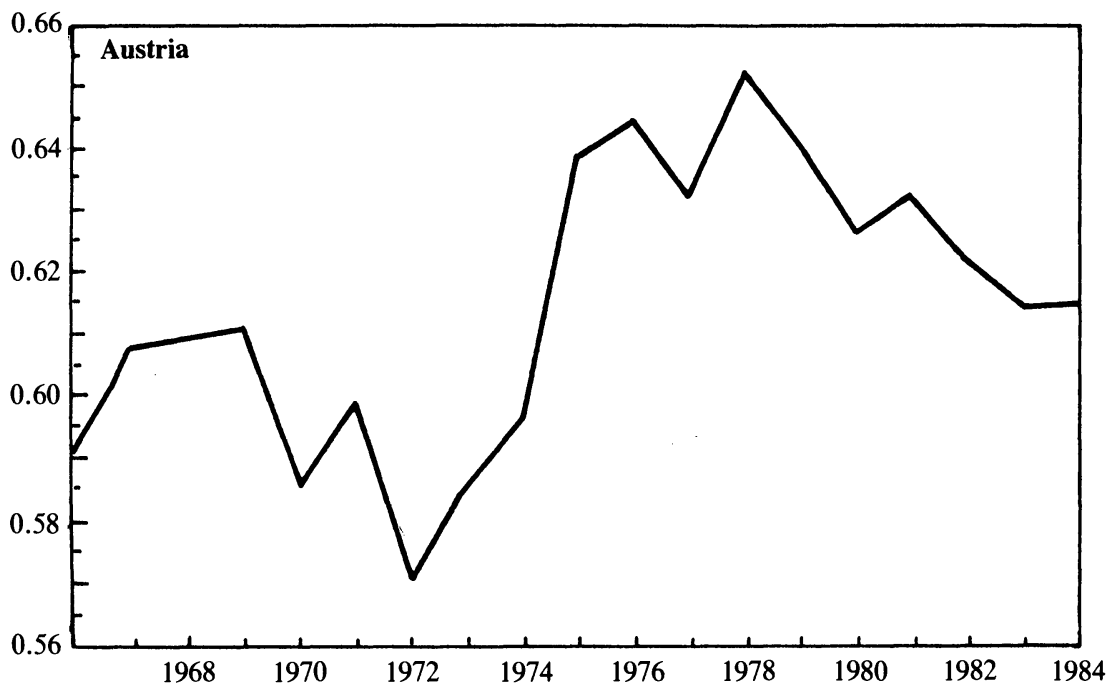

a. Ratio of real wage rate in terms of investment goods prices to actual labor productivity. For the United States, the wage pertains to all workers, including the self-employed. For Austria, Germany, and the United Kingdom, the wage includes employees only. 
components of rental price, the exogenous reduction of the real wage decreased the wage-rental ratio (equation 30). An exogenous downshift of 7 percent in the real wage was accordingly imposed in the solution for the natural growth path during 1974-75, resulting in a corresponding once-for-all reduction in the desired capital-labor ratio and the time path of potential output. Thus part of the deceleration of potential output growth during the subsequent five years or so reflects the gradual transition to a lower growth path. Without this relative price shock adjustment, potential productivity would not respond to the import price shock, and the wage gap would be understated. ${ }^{34}$

Another, equivalent, way of understanding why the potential path must be adjusted for the relative price shock is to examine its effect on the rate of return on capital. As shown earlier, in footnote 17, the rate of return can be expressed as $R=\alpha(P / P I)(Y / \lambda K)-d$. In the United States, the energy shock induced a lasting increase in the price of capital goods, $P I$, relative to the price of final output, $P$, of about 7 percent. To maintain the pre-shock required rate of return of $r$, the marginal product of capital, $\alpha(Y / K)$, must therefore rise, and this requires a decrease in the capitallabor ratio and a corresponding once-for-all drop of the potential output path for the given potential labor path. ${ }^{35}$

The same sort of behavior is observable in figure 4 for the United Kingdom, except that the import price explosion began in 1973 instead of 1974. Just as in the United States, the real wage path drops discontinuously as a result of the supply shock, and the wage-rental ratio is adjusted downward in the potential solution.

34. The effect of this price-induced increase in the relative cost of capital services on actual productivity is captured automatically through the observed wage-rental argument in the estimated factor demand system. For further discussion of the impact of energy shocks as measured in the model, see Robert M. Coen and Bert G. Hickman, "Energy Shocks and Macroeconomic Activity: Simulation Results from the Hickman-Coen Model" (Energy Modeling Forum, Stanford University, November 1983). Other exogenous shocks may also affect the factor price ratio and potential and actual output. Thus the depreciation incentives in the 1981 tax legislation are estimated to have reduced the rental-wage ratio sufficiently to increase the level of potential output, but not the long-run growth rate, by about 1 percent in the 1980s. See Robert M. Coen and Bert G. Hickman, "Tax Policy, Federal Deficits, and U.S. Growth in the 1980s," National Tax Journal, vol. 3 (March 19, 1984), pp. 89-104.

35. A relative price shock cannot affect total factor productivity, which has nothing to do with factor substitution, but it may alter the accompanying level of labor productivity by inducing a movement along the production function to a different capital-labor ratioin this case, to one with less capital and output per worker and a lower potential output path. 
The reaction of the real wage to the oil shock was different in Germany and Austria. The increase in import prices was considerably smaller than it was in the United States and United Kingdom, and nominal wages increased more than investment goods prices. As a result, the real wage rose relative to productivity in both countries in the aftermath of the shock and did not recede much until several years had passed, as shown in figure 4. There is no direct evidence here of an unexpected shock to the potential path such as occurred in the United States and United Kingdom, and no adjustment is made to the potential wage-rental ratio as determined by the productivity trend. This means that the wage gap may be overstated in these countries to the extent that agents may have viewed part of the rise in the real wage as permanently affecting the growth path.

The second oil shock was much smaller in relative terms as indexed by the import price increases during 1979-80. The United Kingdom was by then an oil exporter and the other countries were less dependent on imported oil than before.

Finally, the dollar appreciated one-third between 1981 and 1984, driving down the real price of U.S. imports and investment goods by one-fifth and one-tenth, respectively, with the result that the real investment wage far outpaced the growth of productivity (figure 4). A corresponding adjustment was phased into the potential real investment wage and wage-rental ratio during those years in allowance for the real price shock.

Estimates are required of the full-employment and hypothetical magnitudes in figure 2 . The full-employment estimates have already been described. The hypothetical values of employment, unemployment, and labor force were obtained by simulation methods, using the labor market blocs of the models. To calculate $E A$ and $L A$, the demand and supply functions for labor were solved simultaneously, using the actual values for output and other shift variables external to the labor market, and the potential or full-employment values of the real wage rates entering labor demand and supply. The various shortfalls were then calculated from these solutions and the actual historical data on employment, unemployment, and labor force. ${ }^{36}$

36. In order to purge the calculated shortfalls of stochastic errors, the hypothetical or counterfactual simulations were based on a simultaneous tracking solution of the labor market blocs, in which the single-equation residuals had been added to the stochastic equations for the endogenous variables. 


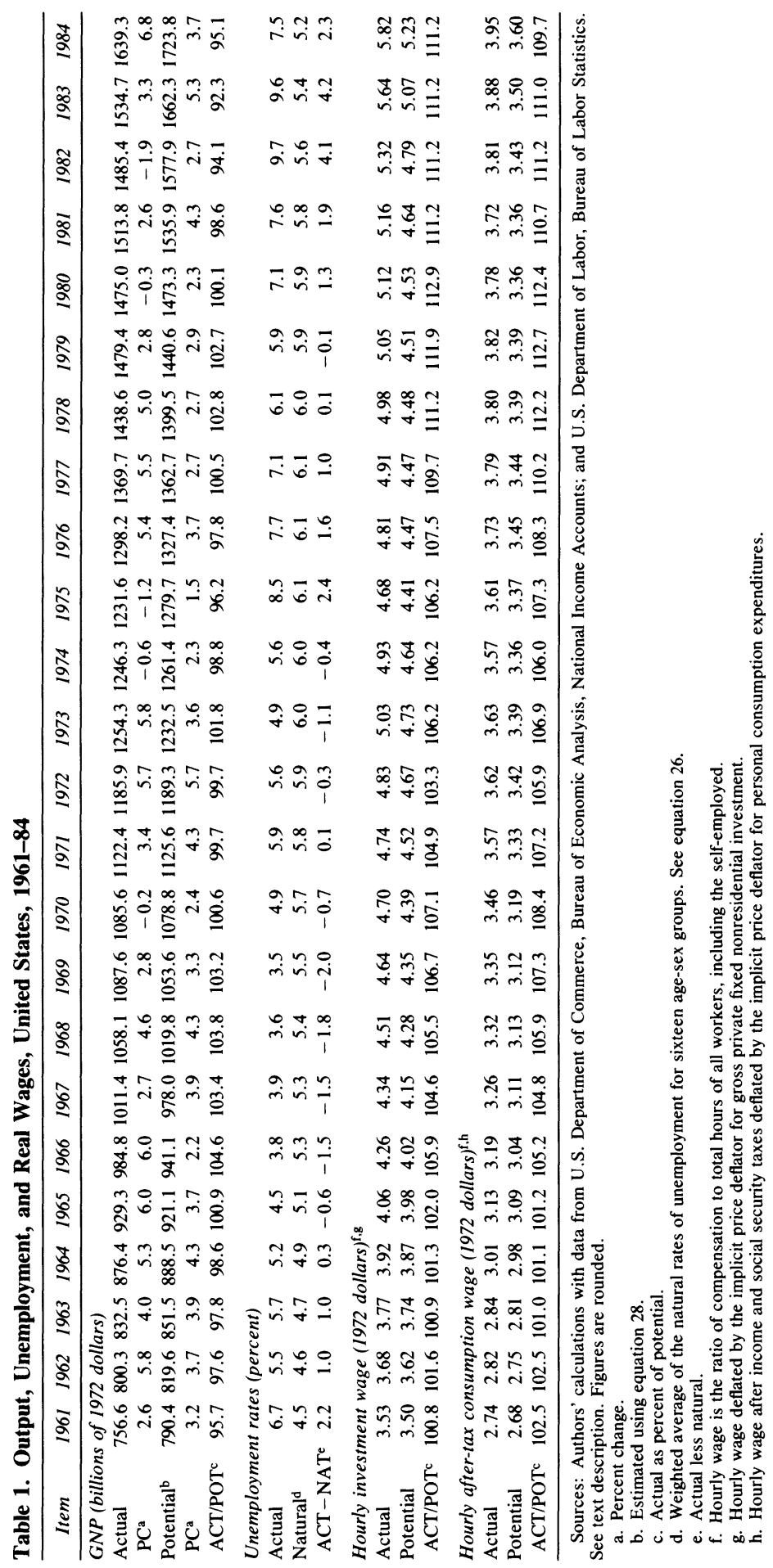


These are partial equilibrium results. No allowance is made for a feedback from the altered values of labor market variables to aggregate demand and output. The procedure is appropriate for measuring the wage and demand components of unemployment, but not for investigating the consequences of an exogenous reduction of real wage rates for the economy as a whole.

\section{Output, Unemployment, and Real Wage History}

It is useful to observe the history of actual and potential gross national product, unemployment, and real wages before examining the unemployment decompositions. Wage gaps are reported for both the investment and consumption concepts of the real wage, but it is the former that is meant by an unmodified reference to the real wage gap.

As shown in table 1, the U.S. economy seldom operated at its potential level during 1961-84, exhibiting instead varying periods of under- and overutilization as measured by the ratio of actual to potential output. The doldrums of the early sixties were succeeded by the Vietnam era of low unemployment and high utilization. The economy did not stray far from potential during 1970-72, but utilization exceeded potential by 2 percent in 1973, before declining in 1974-75 to a low of 96 percent following the oil shock. The subsequent recovery carried the utilization rate to 103 percent during 1978-79, before it again declined to a twentyyear low of 92 percent in 1983, to be followed by a vigorous but incomplete recovery in 1984.

During the 1960s, unemployment exceeded the natural rate whenever actual output fell below potential, and vice versa. This outcome is not a necessary one under the Hickman-Coen concept of the natural growth path of potential output, as it would be in constructs that assume competitive markets for goods and services either explicitly or implicitly. Under competitive conditions, if actual unemployment is at the natural rate, actual output must necessarily be at the full-employment level, because competitive firms choose what output to supply, given wages and prices, at the same time as they choose how much labor to employ. The output resulting from a cleared labor market is therefore by definition at the full-employment level. With price-setting firms and imperfect markets, however, labor demand is conditional on output, which is 


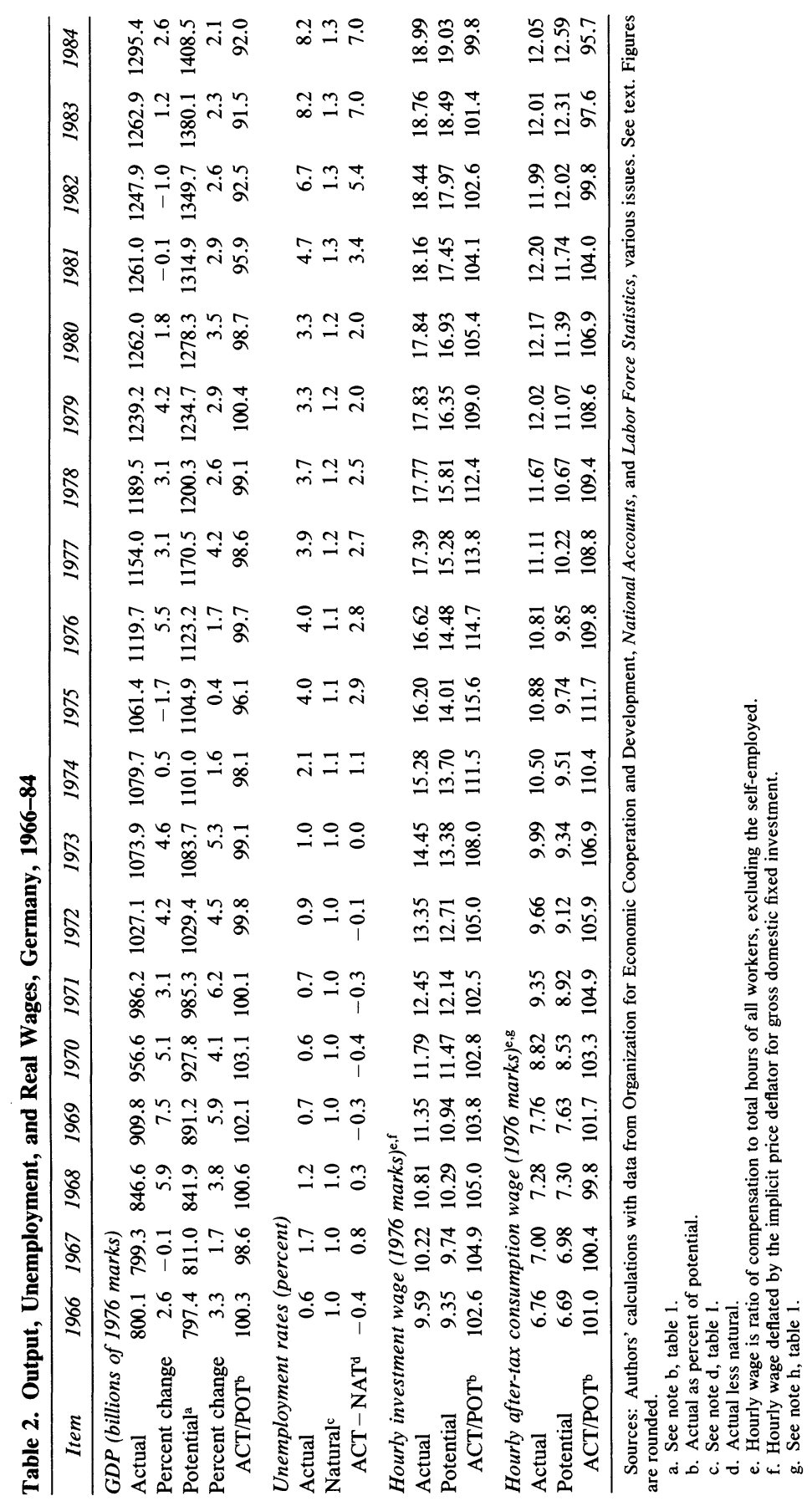


demand-determined in product markets. Unemployment may therefore exceed the natural rate even with output at its potential level, if the real wage is above the level that would prevail if the labor market were to be cleared at potential GNP, or if carryover unemployment exists because of a preceding shortfall.

Such excess unemployment actually occurred with the economy slightly above potential in 1977 and in 1980 because the real wage gap $(W R / W R F)$ was positive and large, as shown in the third and fourth panels of the table. ${ }^{37}$ Of course, effective demand may also occasionally offset the adverse effects of a large wage gap, as it did in 1978-79, when unemployment was reduced to the natural level by high effective demand as reflected in a utilization rate of 103 percent.

The wage gap was small or negative during the early 1960s, so that classical unemployment could not have been an important problem. The wage gap rose to successively higher plateaus during the Vietnam War years and in the mid-1970s and early 1980s, however, increasing its unemployment impact.

Similar capsule histories of output, unemployment, and real wage gaps are presented for Germany and Austria in tables 2 and 3. Germany grew rather steadily and operated close to potential output and the natural employment rate during most of 1966-73, except for the mild recession of 1967 and the subsequent overheating that culminated in the wage explosion of 1970. Growth in Austria was even steadier during 1966-73, unemployment was never excessive, and output did not rise much above potential until the final year. Real wages were moderately high in Germany during this period, paralleling the contemporary experience in the United States, but in Austria they did not deviate much from the potential level.

The unemployment situation deteriorated markedly in Germany following the energy shock, with the actual rate rising from 1.0 percent in 1973 to 8.2 percent in 1984 as the natural rate scarcely increased. The real wage gap increased sharply during 1973-75 and trended downward gradually thereafter, with the economy operating below potential most of the time. In contrast, Austria kept unemployment under control until 1980 by offsetting the real wage gaps that emerged after the oil shock with positive output gaps. Beginning in 1981, however, Austrian expe-

37. Carryover unemployment also contributed to the excess, but it was less important than the real wage gap. 


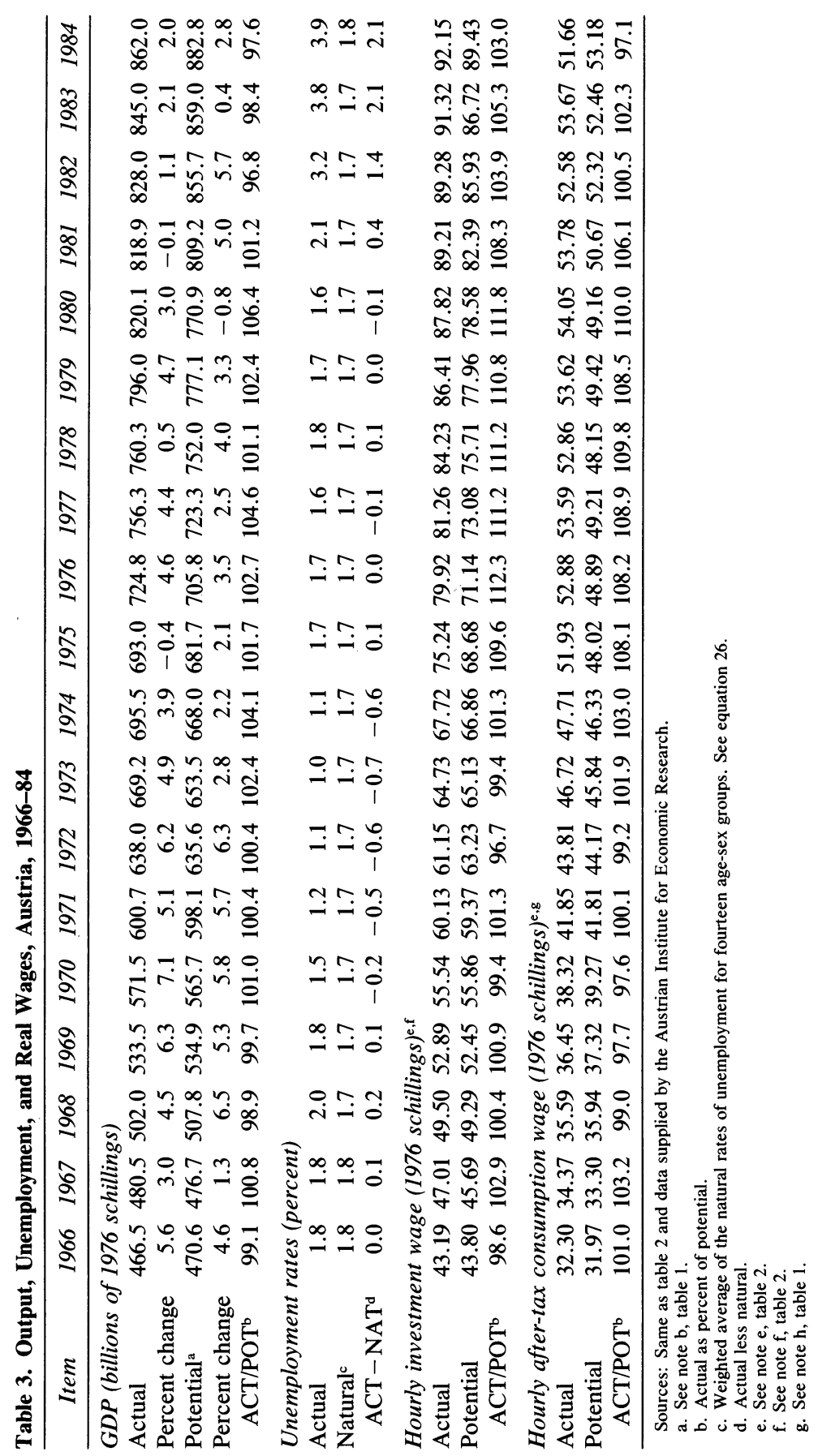


rience followed the German pattern: underutilization of productive potential, rising unemployment, and a declining wage gap.

The United Kingdom experienced moderate excess unemployment during 1967-74, owing to a substantial wage gap that nullified generally high levels of potential utilization (table 4). The wage gap increased 50 percent during 1975-76, drifted downward during the remainder of the decade, and rose again in the eighties. Unemployment rose from 2-3 percent in 1967-75 to about 5 percent in 1976-79 and climbed dramatically thereafter.

\section{Classical and Keynesian Components of Unemployment}

The proximate sources of excess unemployment in the U.S. economy are quantified in table 5 , which reports the measures and decompositions that were defined in equations 33-37.

The natural level of unemployment rose from about 3 million workers in 1961 to more than 6 million in the last half of the 1970s. The estimated excess of actual over natural unemployment was positive in the first half and negative in the second half of the 1960s. Excess unemployment was also negative during 1972-74 and in 1979, but it was positive in 1975-78 and again in 1980-84. The worst years by far were 1982-83, when the excess over natural unemployment is estimated at 4.5 million persons.

Employment was below its natural level (the shortfall was positive) during all but the Vietnam War years 1966-69. That measure of the unemployment problem, however, can be seriously misleading because of hidden unemployment. As shown in the second panel, the volume of hidden unemployment is often substantial, so that elimination of the employment shortfall would reduce unemployment by a considerably smaller amount.

The employment shortfall is factored into its wage and demand components in the third panel, and excess unemployment is similarly decomposed in the final panel. The results confirm that the wage component of unemployment, which was negligible in the early 1960 s, rose moderately during the Vietnam years and the early 1970s and hit new heights thereafter. Between 1965 and 1974 high effective demand more than offset the moderate wage gaps, and excess unemployment 


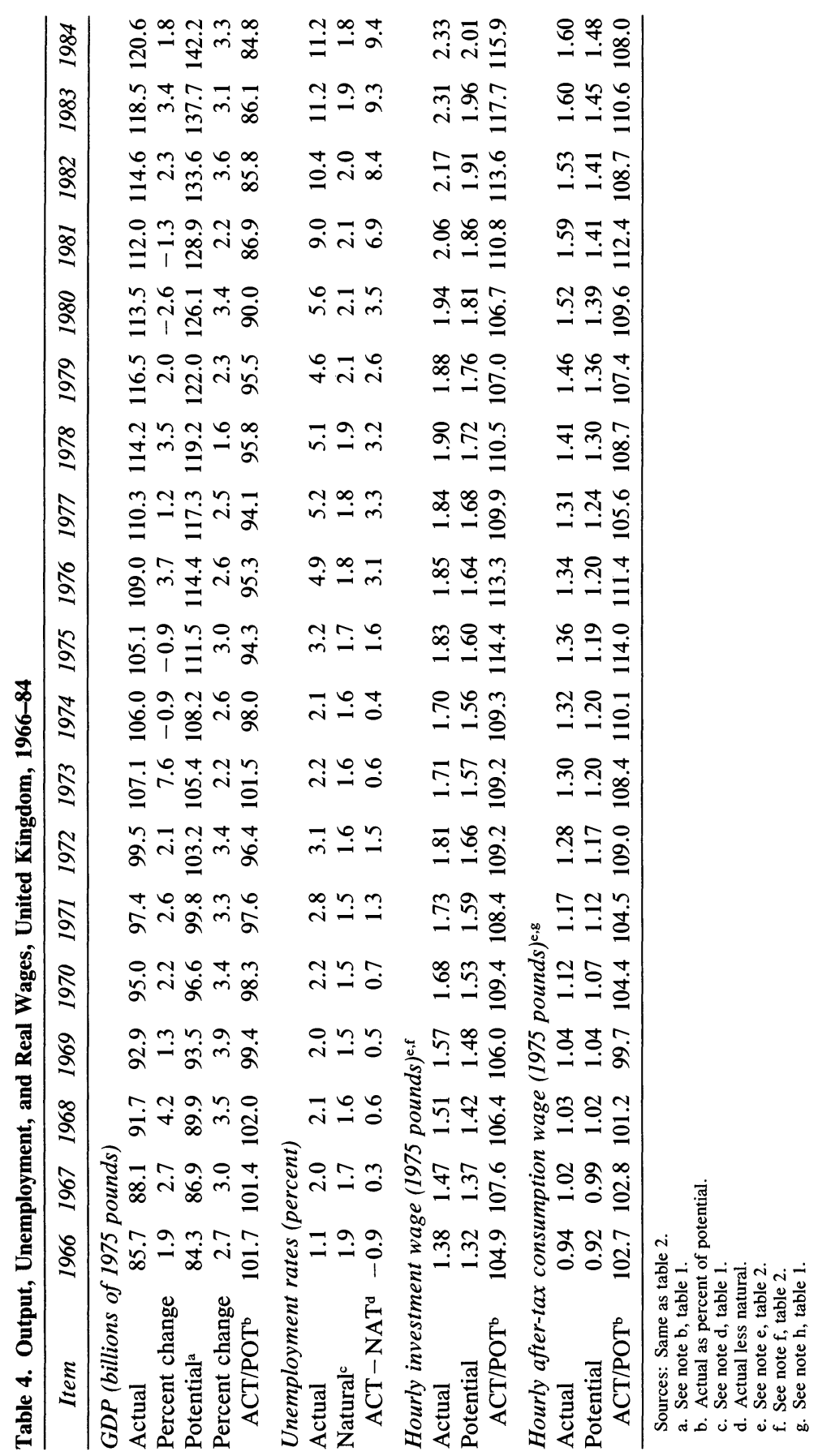




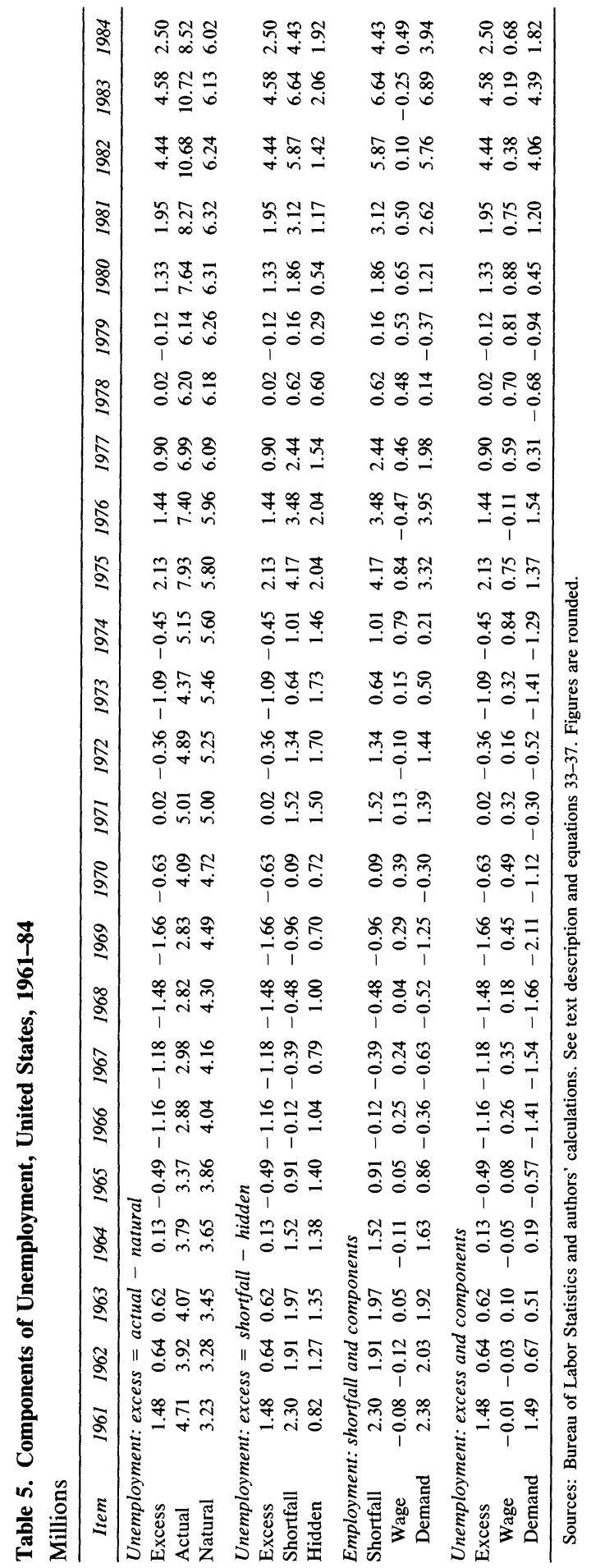




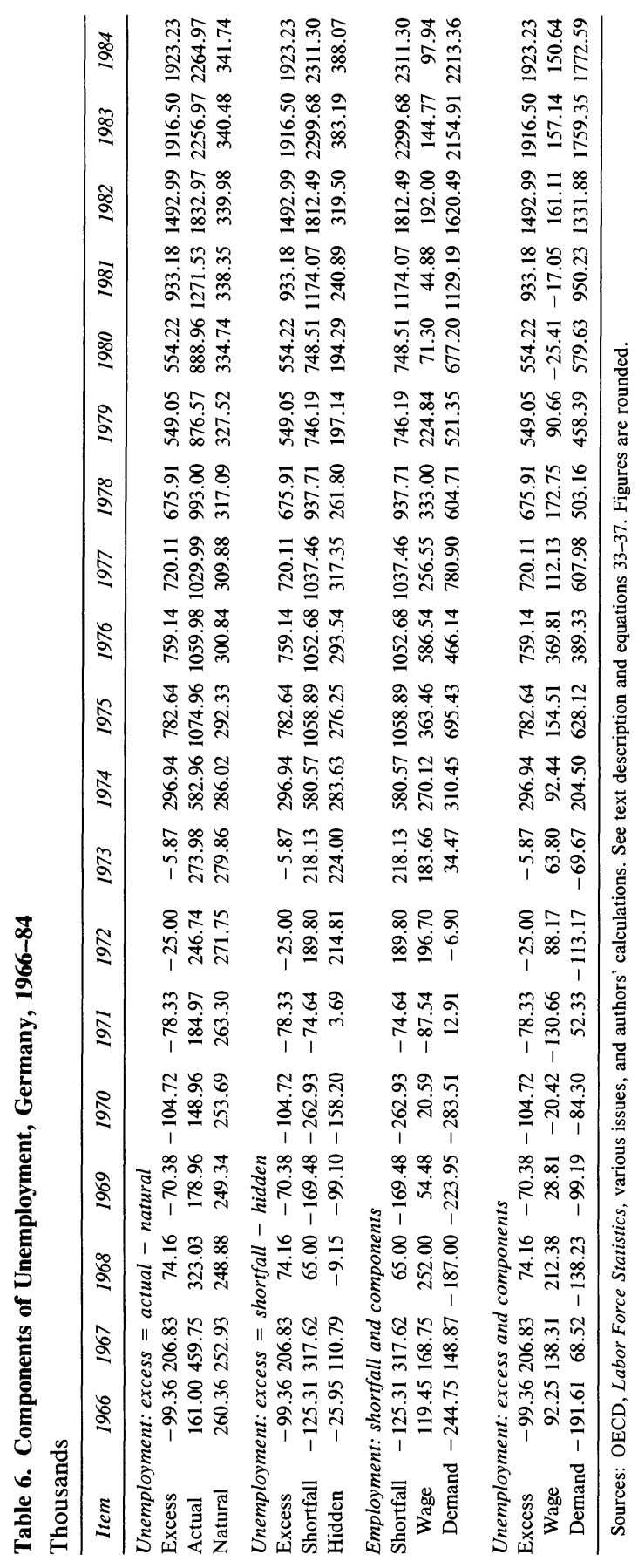


was negative in all years save one. After 1974, however, unemployment exceeded the natural level in most years. During this period of chronically high unemployment, the wage or classical component was the dominant factor in 1977 and 1980, whereas the demand or Keynesian component was the principal depressant during 1975-76 and 1981-84. Finally, high effective demand neutralized the effects of high real wages during 1978-79, as unemployment fell to the natural level for the only period between 1974 and 1984 .

The components of unemployment in Germany are presented in table 6. Unemployment was below the natural level during most years in the later sixties and early seventies, but a chronic positive gap developed in 1974-82. Hidden unemployment, though sizable, was a relatively smaller component of excess unemployment than it was in the United States, because of the low employment elasticity of labor force participation in Germany ( 0.17 as compared with 0.37 in the mid-seventies in the United States). Classical unemployment increased markedly in the mid-seventies, but the Keynesian component was relatively more important even in these years, and it accounted for virtually all of the poor employment performance of 1981-84.

Unlike the United States and Germany, Austria did not experience chronic unemployment after the OPEC oil shock, because of offsetting classical and Keynesian components (see table 7). When excess unemployment did finally appear in 1981-84, it was associated with a demand shortfall rather than a wage gap. Hidden unemployment is substantial in Austria, owing to the largest employment elasticity of labor force participation in the group of four countries (0.48), and was negative more often than not, since the employment shortfall was usually negative.

Excess unemployment in the United Kingdom, which was moderate in 1967-75, rose somewhat in 1976-80 and stayed at markedly higher levels thereafter (table 8). The unemployment of the early years was classical but the balance shifted toward the Keynesian component after the first energy shock, albeit with sizable contributions in most years from the continuing wage gap. The bulk of the rise during the eighties is attributable to a demand shortfall, however, just as it is in Austria and Germany. Hidden unemployment is relatively moderate in the United Kingdom, where the employment elasticity of the labor force is estimated to be 0.22 . 


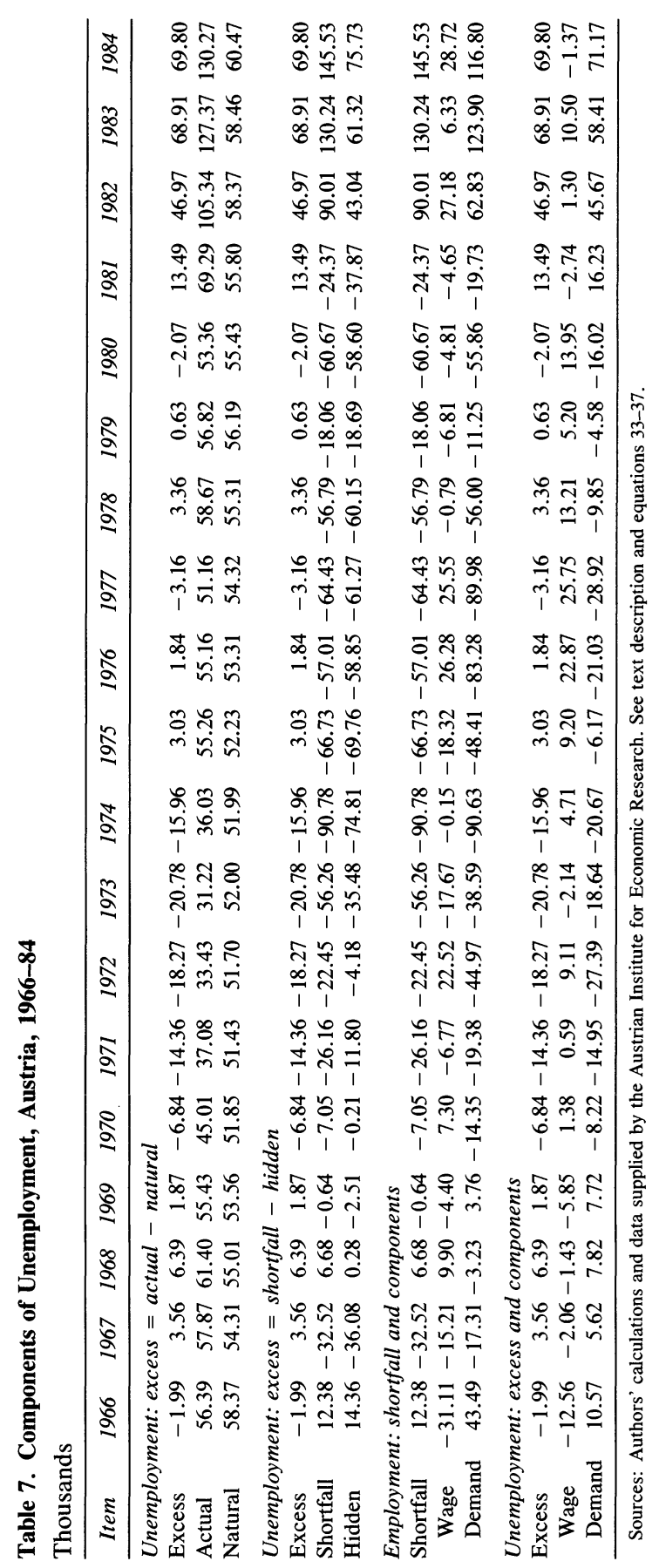




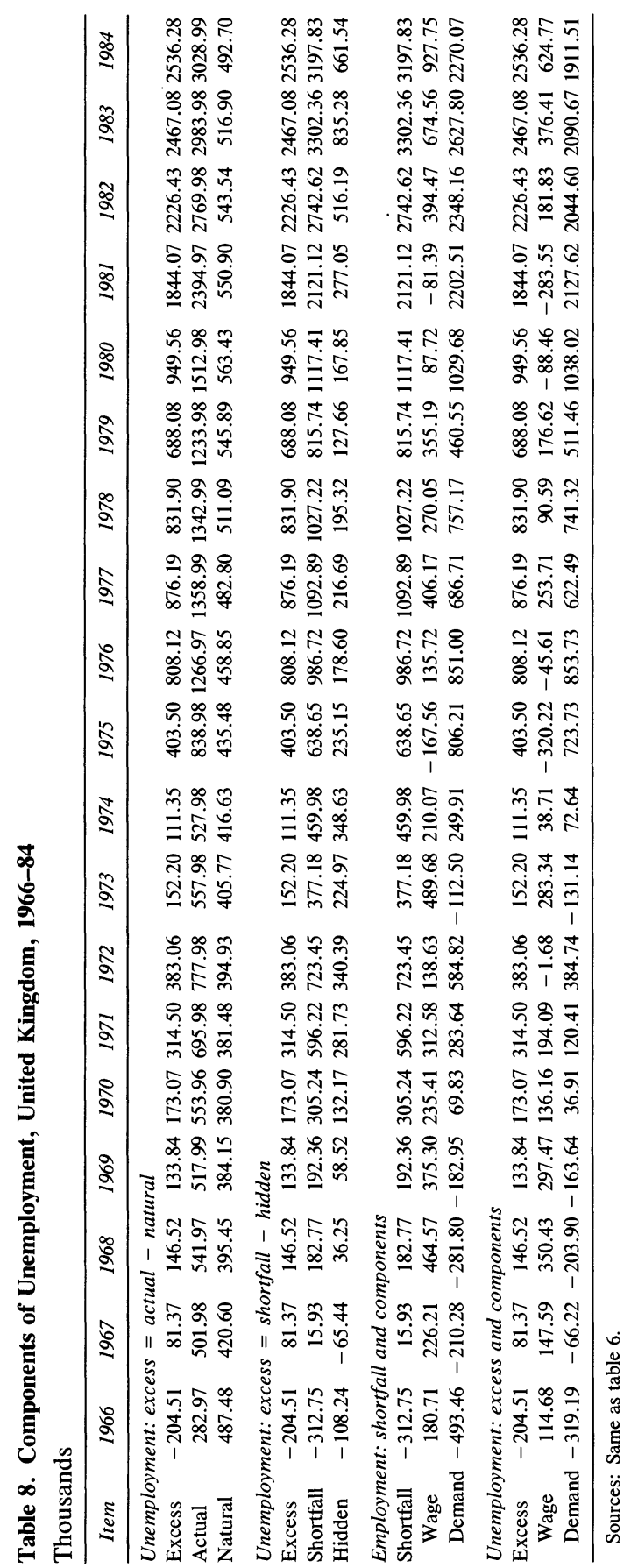




\section{Key Determinants of the Classical Component}

The magnitude of the wage component of the employment shortfall depends on the wage elasticity of labor demand as well as on the size of the wage gap. Given a Cobb-Douglas technology and assuming that adjustment costs keep firms off the long-run production function, the short-run elasticity of man-hour input with respect to the real wage rate, holding constant other components of the wage-rental ratio, is the negative of the product of the capital coefficient in the production function $(\alpha)$ and the adjustment speed of labor input $(f)$. For the United States, the estimated values of these parameters from equation 24 are 0.25 and 0.65 , yielding an estimated wage elasticity for man-hours of -0.16 . The corresponding figures are $0.30,0.65$, and -0.19 for Germany; $0.32,0.58$, and -0.18 for Austria; and $0.24,0.91$, and -0.22 for the United Kingdom. These small elasticities clearly restrict the scope of wage gaps as a cause of unemployment in the various countries, but large wage gaps may still account for substantial unemployment, as we have seen.

An additional complication is introduced by the endogenous response of average working hours to wage changes. In all four countries, the partial wage elasticity of average hours is negative, indicating dominance of the income over the substitution effect, and ranges from -0.04 in the United States to -0.10 in Germany, -0.17 in Austria, and -0.19 in the United Kingdom. Thus the direct result of a real wage reduction is to increase average hours, partly nullifying the favorable impact of increased man-hour demand on employment.

In the model of Germany, the response of average hours is confined to the direct impact of the wage reduction, so that the total employment elasticity is the difference between the elasticities for man-hours and average hours, or $-0.09 .{ }^{38}$ Although the partial elasticities for the other countries are also negative and therefore operate to weaken the employment response to a wage change, the total response of average hours also includes the effects of induced changes in other employment or labor force variables and cannot be directly estimated from the partial

38. The consumption wage gap in Germany was negative in 1982-84, so that reversion to the full-employment consumption wage reduces average hours and reinforces the favorable impact of the reduction in the investment wage on employment (tables 2 and 6). 
elasticities. The total response of average hours is small in any event for the United States, but it appears to be substantial for the other countries.

Many empirical analyses of the effects of real wages on unemployment neglect the role of induced variations in average hours by measuring labor input by employment rather than man-hours in production or labor demand functions or in reduced-form equations for employment or unemployment. Our results suggest that this is a serious omission in view of the offsetting effects of wage changes on man-hours and average hours of work.

The contribution of a wage gap to an employment shortfall depends only on the elasticity of demand for labor input and the overall responsiveness of average hours, whereas the wage component of excess unemployment is additionally affected by the induced labor force response to the hypothetical wage change. The small wage elasticities in the labor force participation equations for Germany and the United States $(-0.04$ and -0.01$)$ severely constrain the direct impact of wage reductions on the labor force, but in the United Kingdom and Austria, the wage elasticities are large enough $(-0.07$ and 0.11$)$ to exert a moderate effect on the labor force. As noted above, moreover, the employment elasticities are substantial in all the countries, so that a considerable portion of the employment gain from a wage reduction would be nullified by an additional influx to the labor force.

\section{Potential and Full-Employment Output}

In this section we compare the empirical measures of potential and full-employment output, as calculated from equations 28 and 40 , in tables 9-12. Also included are utilization indexes measuring the ratio of actual output to potential and full-employment output, plus the ratio of fullemployment to potential output. The utilization rate of full-employment output is a direct indicator of the amount of output change that would eliminate the Keynesian component of unemployment in a given year. The potential utilization rate is the preferred measure of overall resource utilization, since it shows the extent to which an economy adheres to its natural growth path embodying full employment of labor and capital at normal intensities.

In the United States, the difference between potential and full- 


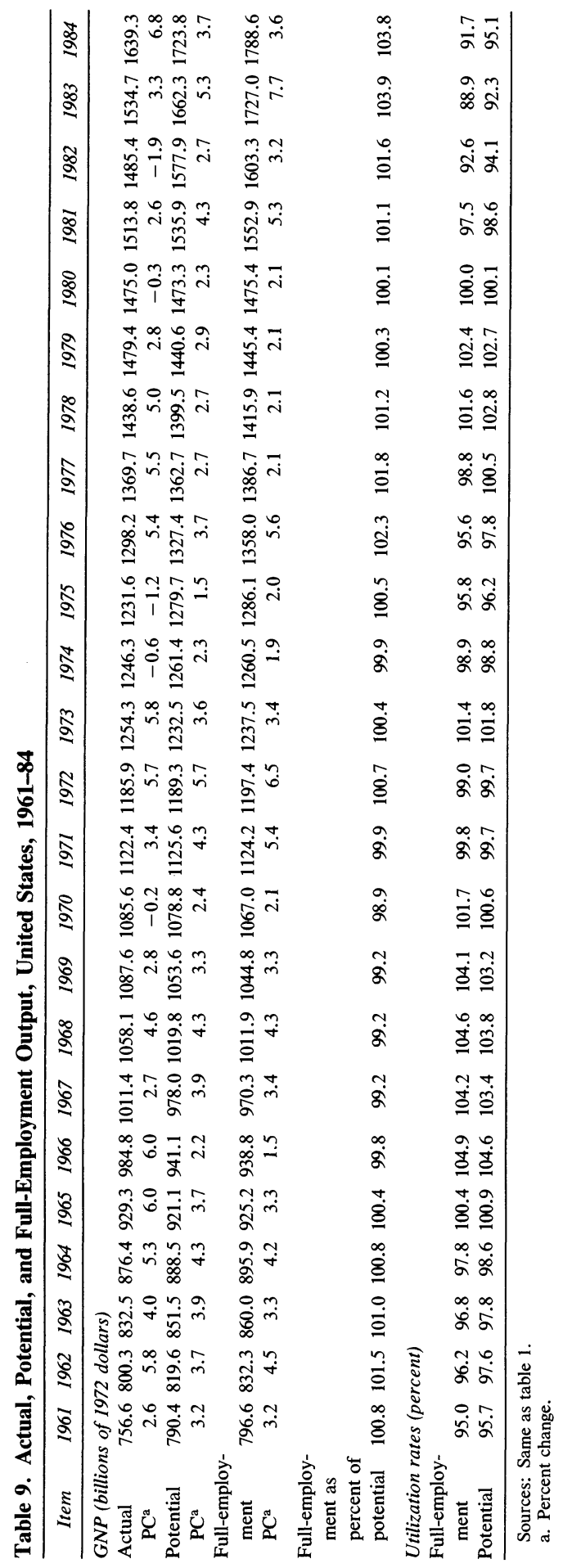




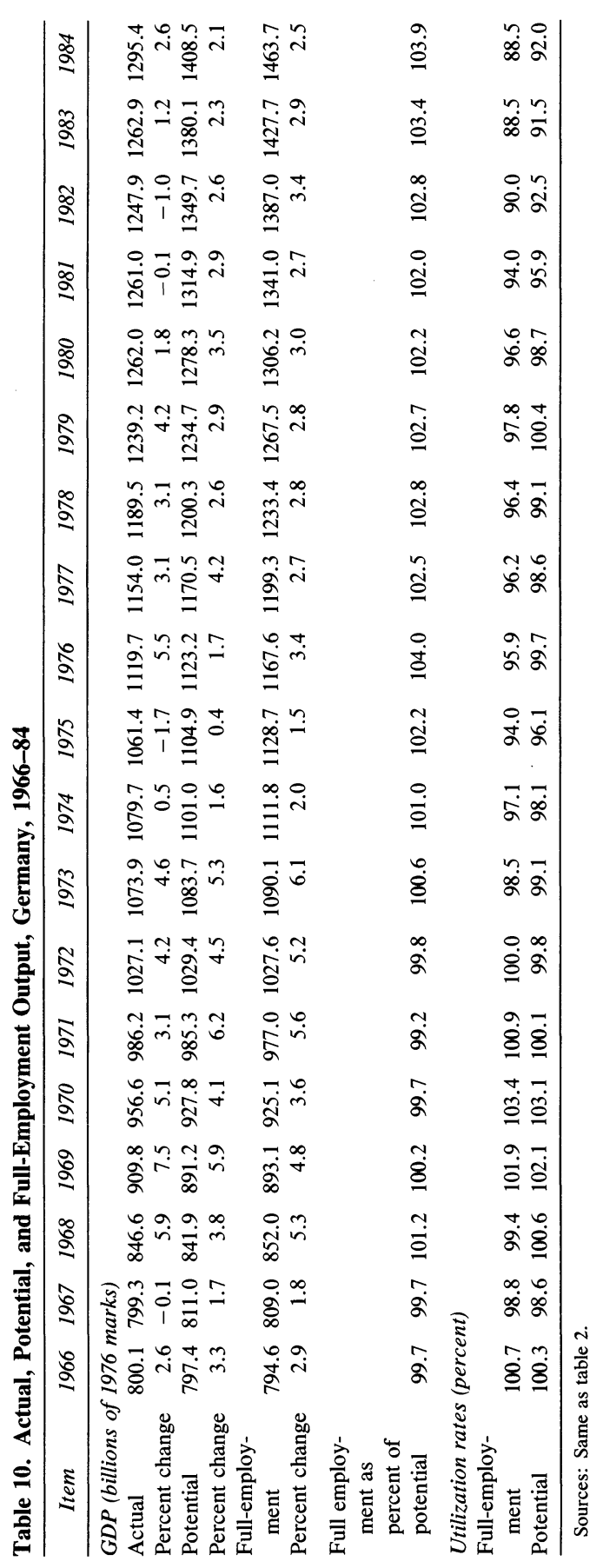




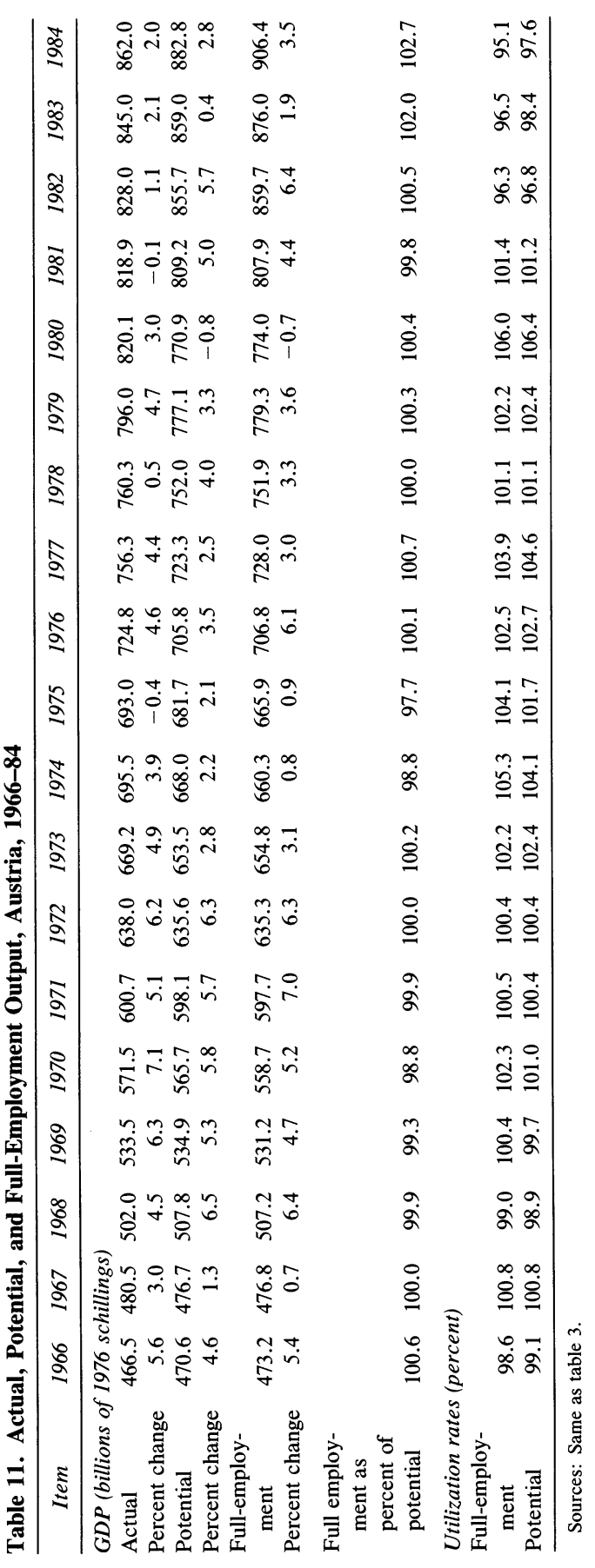




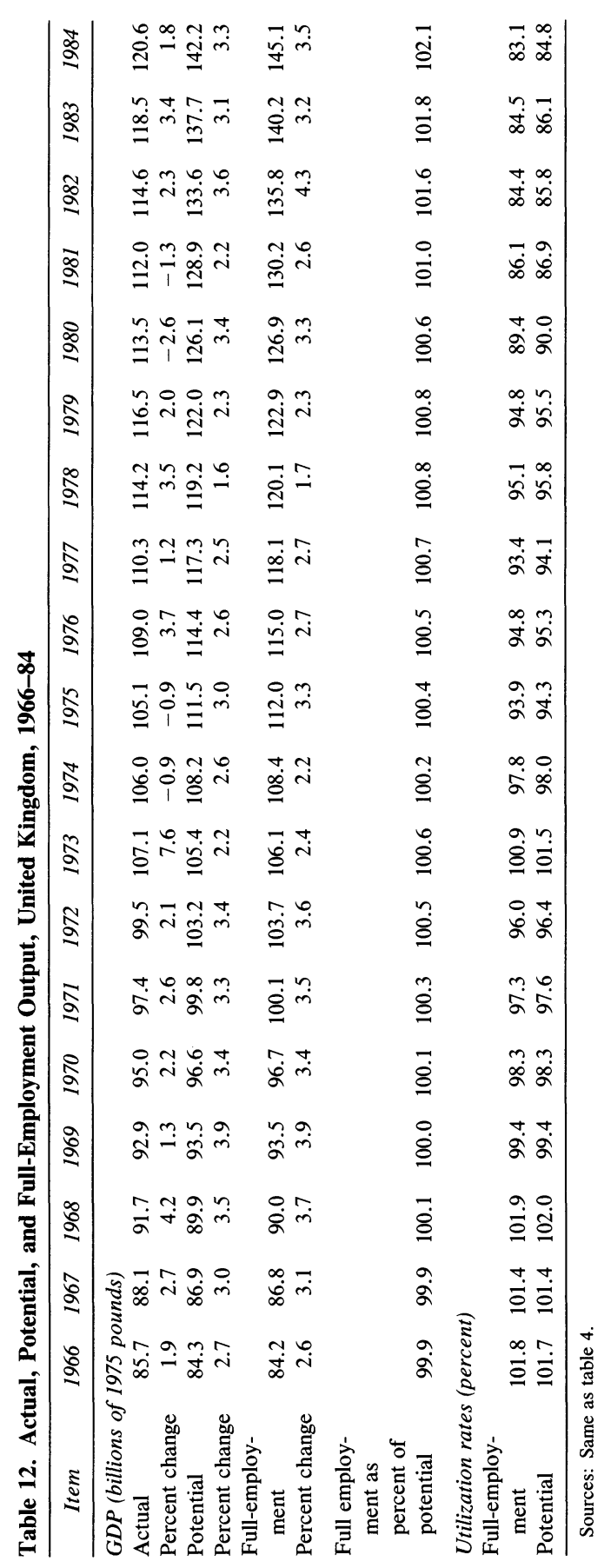


employment output seldom exceeded 1 percent, and the utilization rates were correspondingly close until 1983-84. The same was true of Germany during the late sixties and early seventies, but the ratio of full-employment to potential gross domestic product exceeded 2 percent throughout 1975-84 and reached 4 percent in 1976 and 1984. The two measures were close in most years for Austria until the doldrums of 1983-84. The gap between potential and full-employment output tends to be small in the U.K. model, owing to the rapid adjustment speed estimated for the labor demand function ( 0.9 as compared with about 0.6 for the other countries), but the margin between the two nonetheless increased substantially in the eighties as the employment shortfall cumulated.

\section{More on the Wage Gap and Classical Unemployment}

The pioneering wage-gap analysis of Sachs and Bruno attached considerable importance to the emergence in the 1970s of large disparities between the real wage "warranted" by full-employment productivity and the realized product wage in many industrialized countries:

In the late 1960s and early 1970s, a real wage explosion (particularly in Europe and Japan) caused a major shift of income distribution away from profits and toward labor. Even before the oil shocks, therefore, many OECD countries faced a major problem of declining profitability and slowing growth. In the second phase real wages did not decelerate (outside of the United States) to make room for the raw material price increases, so the profit squeeze intensified. In the third phase low profitability and rising unemployment slowed the rate of capital accumulation and productivity growth. Real wage increases were reduced, but so too was productivity growth, with the result that the excess of wages over full-employment productivity persisted into the early $1980 \mathrm{~s} .{ }^{39}$

Thus some, but by no means all, unemployment was induced from the supply side by price shocks and excessive labor costs:

We have suggested that the sharp increases in unemployment during 1973-75 and 1979-82 are mostly demand-induced and resulted from the application of tight monetary policies to the supply shocks and high inflation in 1972-73 and 1979-80. The steady rise in unemployment during 1975-79 in most of the OECD,

39. Bruno and Sachs, Economics of Worldwide Stagflation, p. 167. See also Jeffrey D. Sachs, "Wages, Profits, and Macroeconomic Adjustment: A Comparative Study," BPEA, 2:1979, pp. 269-319. 
Table 13. Comparison of Real Wage Gap Estimates, United States, Germany, and the United Kingdom, Selected Years, 1965-83

\begin{tabular}{lrrrrrrrr}
\hline \multicolumn{1}{c}{ Estimate } & $1965^{\mathrm{a}}$ & 1970 & 1973 & \multicolumn{1}{c}{1976} & 1979 & 1981 & 1982 & 1983 \\
\hline & & \multicolumn{7}{c}{ United States } \\
Bruno-Sachs 1 & 1.2 & -1.3 & 3.1 & 0.6 & 4.0 & 5.0 & 5.3 & 4.9 \\
Bruno-Sachs 2 & 0.2 & 0.1 & 6.0 & 2.9 & 6.8 & 8.1 & 8.6 & 8.4 \\
Coen-Hickman 1 & 2.0 & 7.1 & 6.2 & 7.5 & 11.9 & 11.2 & 11.2 & 11.2 \\
Coen-Hickman 2 & 1.2 & 8.4 & 6.9 & 8.3 & 12.7 & 10.7 & 11.2 & 11.0 \\
& & & \multicolumn{7}{c}{ Germany } & & & \\
Bruno-Sachs 1 & 1.7 & 1.9 & 8.0 & 14.0 & 14.6 & 17.1 & 13.3 & 9.6 \\
Bruno-Sachs 2 & 2.0 & 1.5 & 7.2 & 13.0 & 15.3 & 19.1 & 15.9 & 12.9 \\
Coen-Hickman 1 & 2.6 & 2.8 & 8.0 & 14.7 & 9.0 & 4.1 & 2.6 & 1.4 \\
Coen-Hickman 2 & 1.0 & 3.3 & 6.9 & 9.8 & 8.6 & 4.0 & -0.2 & -2.4 \\
& & & \multicolumn{7}{c}{ United Kingdom } & & & \\
Bruno-Sachs 1 & -1.5 & 1.5 & 3.1 & 8.1 & 9.3 & 14.3 & 13.9 & 13.9 \\
Bruno-Sachs 2 & -2.0 & 2.2 & 4.6 & 11.0 & 16.4 & 24.1 & 25.0 & 26.4 \\
Coen-Hickman 1 & 4.9 & 9.6 & 9.2 & 13.3 & 7.0 & 10.8 & 13.6 & 17.7 \\
Coen-Hickman 2 & 2.7 & 4.4 & 8.4 & 11.4 & 7.4 & 12.4 & 8.7 & 10.6 \\
\hline
\end{tabular}

Sources: Bruno-Sachs estimates of the real value-added wage gap in manufacturing are from Michael Bruno, "Aggregate Supply and Demand Factors in OECD Unemployment: An Update," Economica, vol. 53 (Supplement, 1986), pp. S35-S52. Variant 1 assumes that the wage gap was zero on average during 1965-69 and uses the average growth rate of labor productivity during 1960-73 and 1973-85 as the full-employment trend. Variant 2 corrects for the effect of the unemployment level and its changes on full-employment productivity growth using a regression of realized productivity on a time trend (with a trend break in 1975) and the unemployment variables. Coen-Hickman estimates of the real wage gap in terms of investment goods (variant 1) and consumption goods (variant 2) are from tables 1,2 , and 4 .

a. 1966 for Germany and the United Kingdom in the Coen-Hickman estimates.

however, should be attributed to the fact that real wages remained above marketclearing levels in most economies (but probably not in the United States). ${ }^{40}$

These capsule summaries are based on an impressive array of theoretical and empirical analyses, from among which we can comment only on two or three issues related to our own estimates.

\section{WAGE GAP ESTIMATES}

Table 13 compares our estimates with those of Bruno and Sachs as updated through 1983.41 The following points should be borne in mind when examining the table.

-The Bruno-Sachs estimates are for the real value-added wage in manufacturing; our estimates, for the economywide real wage in terms of capital goods prices.

40. Bruno and Sachs, Economics of Worldwide Stagflation, p. 171.

41. Michael Bruno, "Aggregate Supply and Demand Factors in OECD Unemployment: An Update," Economica, vol. 53 (Supplement, 1986), pp. S35-S52. 
-The Bruno-Sachs measures are conceptually based on the assumption of output market clearing with competitive firms operating on the notional labor demand function, equation 2, whereas ours assume imperfect competition and the conditional labor demand function, equation 6.

-Both approaches assume a Cobb-Douglas technology, with the fullemployment real wage following the trend of full-employment productivity. They differ substantially, however, in the method of determining the productivity trend, and Bruno and Sachs offer two variants of the productivity trend and wage gap series. The first of their measures shown in the table assumes that the wage gap was zero on average during 1965-69 and takes the average growth rate of measured labor productivity during 1960-73 and 1973-85 to represent the respective full-employment trend. In the second variant-the adjusted wage gaps-they attempt to correct for the effect of the unemployment level and its changes on fullemployment productivity growth using an ad hoc regression of realized productivity on time, with a trend break in 1975, and the unemployment variables. In our measures the potential productivity path is endogenously determined by a structural econometric model of labor supply and demand, where the latter incorporates the parameters of the production function and the adjustment process. The wage gap is not normalized to zero in the late sixties because our framework does not assume that the existence of approximately full employment necessarily implies that the labor market is clearing at the observed wage rate.

According to both measures, the real wage explosion before the first energy shock was pronounced in Germany. Bruno and Sachs's finding that the wage gap also increased substantially in the United States during $1970-73$ is puzzling and probably reflects a sizable underestimate of the gap for 1970, owing to their normalizing assumption that the labor market was in equilibrium during 1965-69 despite the overheating associated with the Vietnam War. The estimated wage gap in our annual growth model, in contrast, was rather large in 1970 and actually fell during the next three years of higher unemployment. The U.K. gap in our estimates was also much higher in 1970-73 than during the late sixties.

Bruno and Sachs's finding of a sharp increase in the wage gap in Germany and the United Kingdom between 1973 and 1976 in reaction to the first oil shock is confirmed in our measures. For the United States, our estimated gap increases somewhat during this period, whereas their 
figure declines substantially. The increase reflects our downward adjustment of the potential path of labor productivity in response to the oil shock as described above.

Both studies show a decline in the German wage gap during the early 1980s. The decline began much earlier in our estimates, however, with the gap narrowing gradually in 1976-79 and rapidly thereafter. By 1983 the gap had virtually disappeared in our measure but was still large in the Bruno-Sachs measures.

The wage gap for the United States rises during the early eighties in the Bruno-Sachs estimates. The gap decreases slightly after 1979 in our estimates, but even so it remains above the Bruno-Sachs estimates.

In our estimates the wage gap for the United Kingdom decreases during 1976-81 and rises again in 1981-83, whereas the Bruno-Sachs measures rise steadily after 1976 . By 1983 their two variants bracket our estimate.

\section{WAGE GAPS AND LABOR DEMAND}

The initial theoretical derivations by Bruno and Sachs relating the real wage gap to the employment gap are explicitly based on the unconstrained competitive model, implying that all unemployment is classical and that eliminating the wage gap would restore full employment. ${ }^{42}$ However, they do not in fact use the competitive demand curve for labor to evaluate the employment effects of real wages, since they share our distrust of the restrictive assumptions of the competitive model, namely, that firms are generally not demand-constrained and are usually on their production frontiers and notional supply schedules. Instead, they "modify the conventional demand curve for labor by assuming gradual adjustment as well as a short-run role for aggregate demand factors." ${ }_{43}$ Thus their reduced-form equations for labor input in manufacturing, although conditional on capital stock, also include demand variables along with the real wage rate. Similarly, their reducedform equations for aggregate unemployment include the adjusted wage gaps estimated for manufacturing as proxies for the corresponding

42. Bruno and Sachs, Economics of Worldwide Stagflation, chap. 9; Bruno, "Aggregate Supply and Demand Factors."

43. Bruno, “Aggregate Supply and Demand Factors," p. S45. 
aggregative measures, along with real money balances, the government deficit, and world trade as demand variables, but omit capital stock. ${ }^{44}$

It is noteworthy that their unemployment regressions attribute much less importance to the wage gap than is implied by the competitive theory. Recall that, under a Cobb-Douglas technology, the elasticity of employment with respect to the real wage for a competitive, profitmaximizing firm in the short run is the reciprocal of the capital elasticity in the production function, or about 3 or 4 for realistic values of the capital elasticity. In interpreting the results of a pooled unemployment regression for eight countries that is representative of their findings, Bruno reports that for each 1 percent rise or fall in the wage gap, the unemployment rate rises or falls by 0.15 percent within two years. ${ }^{45}$ This short-run elasticity of about 0.15 resembles our estimates and is far below the value of 3 or 4 that one would predict from the competitive model of a firm's labor demand decision under unconstrained profit maximization.

According to these recent findings of Bruno, there was essentially no wage-related unemployment in the United States during 1970-82; demand and wage factors were about equally prominent in Germany during the same period, but the role of demand was rising toward the end; and the wage gap was the dominant influence in the United Kingdom throughout the period, but with demand restraint assuming increasing importance after 1978. Our own estimates give much less weight to the wage factor in Germany and the United Kingdom, but agree that demand constraints became relatively more important in the 1980s in both countries. On the other hand, the wage gap plays a larger, though still subsidiary, role in our analysis of U.S. unemployment.

\section{Investment Demand and Productivity}

Part of the Bruno-Sachs thesis is that the supply-induced wage gaps of the first half of the seventies led to a third phase of low profitability and rising unemployment that slowed the rate of capital accumulation and productivity growth, thereby tending to perpetuate the wage gaps.

44. See Bruno, "Aggregate Supply and Demand Factors." This specification is a modification of the one appearing in Bruno and Sachs, Economics of Worldwide Stagflation, chap. 10.

45. Bruno, “Aggregate Supply and Demand Factors,” p. S48. 
In 1986 Bruno estimated rate-of-profit and investment equations for eight countries that led to the general conclusion that output contraction from the demand side was the dominant factor in the profit squeeze and investment contraction, with high real wages playing only a small direct role in the reduction of capital formation. Bruno's findings are in general accord with our own, but our interpretation is rather different, especially as regards the relationship between investment and productivity growth.

Our investment demand function, equation 25 , depends on expected rather than realized profitability and is derived jointly with the labor demand equation on the assumption of cost minimization. Investment therefore depends on the wage-rental ratio, and hence on the real wage rate in terms of investment goods, as well as on output and technical progress.

Along the natural growth path, the level of man-hour productivity (equation 31) is governed by the rate of technical progress (growth rate of total factor productivity); the equilibrium capital-labor ratio, which in turn depends on the equilibrium wage-rental ratio; and the growth rate of full-employment man-hours. As we have shown elsewhere, the last term is an implicit measure of the intensity of use of employed manhours. ${ }^{46}$ The contributions of these three components to potential productivity growth before and after 1973, as calculated from our factor demand estimates, are shown in the first four columns of table 14.

The rate of technical progress decelerated after the early seventies in all the countries in our sample, as did potential productivity growth. The rate of growth of the full-employment real wage also decreased in line with the slowdown in productivity growth (equation 29), thereby moderating the secular increase in the wage-rental ratio, reducing the rate of capital deepening, and further slowing productivity growth. Thus the slowdown in technical progress induced a decline in capital deepening, and hence in the net investment requirement to sustain the natural growth path of output. The causation runs from reduced productivity growth to reduced investment, rather than the reverse. In the cases of the United Kingdom and United States, real investment demand was also reduced by the unexpected exogenous drop in the investment wage and wagerental ratio resulting from the first oil shock.

Table 15 compares the actual and potential shares of investment in

46. Coen and Hickman, "The Natural Growth Path." 


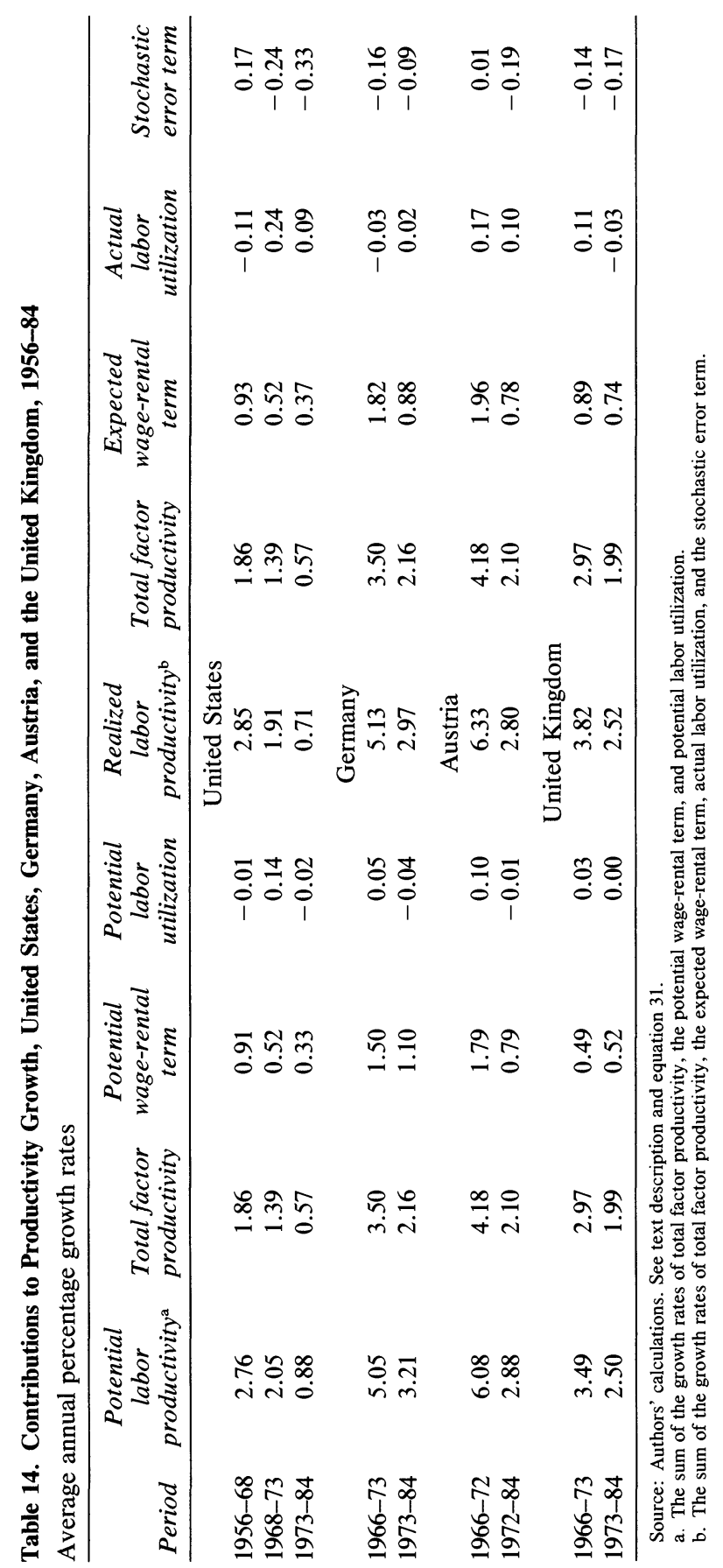


Table 15. Investment Shares of Gross National Product, United States, 1956-84, and of Gross Domestic Product, Germany, Austria, and the United Kingdom, 1966-84

Percent

\begin{tabular}{|c|c|c|c|c|}
\hline \multirow[b]{2}{*}{ Period } & \multicolumn{2}{|c|}{ Natural ${ }^{\mathrm{a}}$} & \multicolumn{2}{|c|}{ Realized $^{\mathrm{b}}$} \\
\hline & $\mathrm{Net}$ & Gross & $\mathrm{Net}$ & Gross \\
\hline \multicolumn{5}{|c|}{ United States } \\
\hline $1956-68$ & 2.40 & 9.50 & 2.42 & 9.58 \\
\hline $1968-73$ & 2.37 & 10.01 & 2.60 & 10.49 \\
\hline $1973-84$ & 1.99 & 10.29 & 2.09 & 10.96 \\
\hline \multicolumn{5}{|c|}{ Germany } \\
\hline $1966-73$ & 10.29 & 22.17 & 11.69 & 23.78 \\
\hline $1973-84$ & 7.78 & 20.40 & 7.07 & 21.37 \\
\hline \multicolumn{5}{|c|}{ Austria } \\
\hline $1966-72$ & 10.02 & 25.2 & 10.80 & 25.95 \\
\hline $1972-84$ & 7.90 & 23.78 & 8.46 & 24.87 \\
\hline \multicolumn{5}{|c|}{ United Kingdom } \\
\hline $1966-73$ & 9.89 & 18.91 & 11.26 & 20.50 \\
\hline $1973-84$ & 7.15 & 17.24 & 6.58 & 17.98 \\
\hline
\end{tabular}

Sources: Authors' calculations with data cited in tables 1-4.

a. See text description accompanying equation 32 .

b. For the United States, unpublished estimates of private, nonresidential net capital in constant prices were prepared by the Bureau of Economic Analysis; for Germany and the United Kingdom, benchmark estimates of real net capital, including residential and government capital, from OECD, Flows and Stocks of Fixed Capital (OECD, 1983); for Austria, estimate was derived from a study of gross capital stocks by Franz Hahn and Ingo Schmoranz, "Schaetzung des oesterreichischen Kapitalstocks nach Wirtschaftstbereichen," Monatsberichte, Austrian Institute for Economic Research, vol. 56 (1983), pp. 40-52. Equation 32 in the text was applied recursively to generate capital stock series from the benchmarks, using real gross investment expenditures from the national accounts.

aggregate output. For the United States and Austria the realized shares are larger, so that actual capital formation exceeded the investment requirements for potential output during the seventies and eighties. ${ }^{47}$ The same was true of Germany and the United Kingdom for most of the period. The upshot is that in 1984 the actual capital stock equaled the potential requirement in Germany and the United Kingdom and exceeded it by 7.5 percent in the United States and 3.5 percent in Austria. Clearly output was not constrained by insufficient physical capital in any of these countries during this period.

Even were the actual capital stock to fall below the potential requirement, there would be no permanent loss of potential productivity, since the investment deficiency could be made good in the future and the

47. This is true even when allowance is made for the fact that realized investment is expressed as a share of actual instead of potential output. 


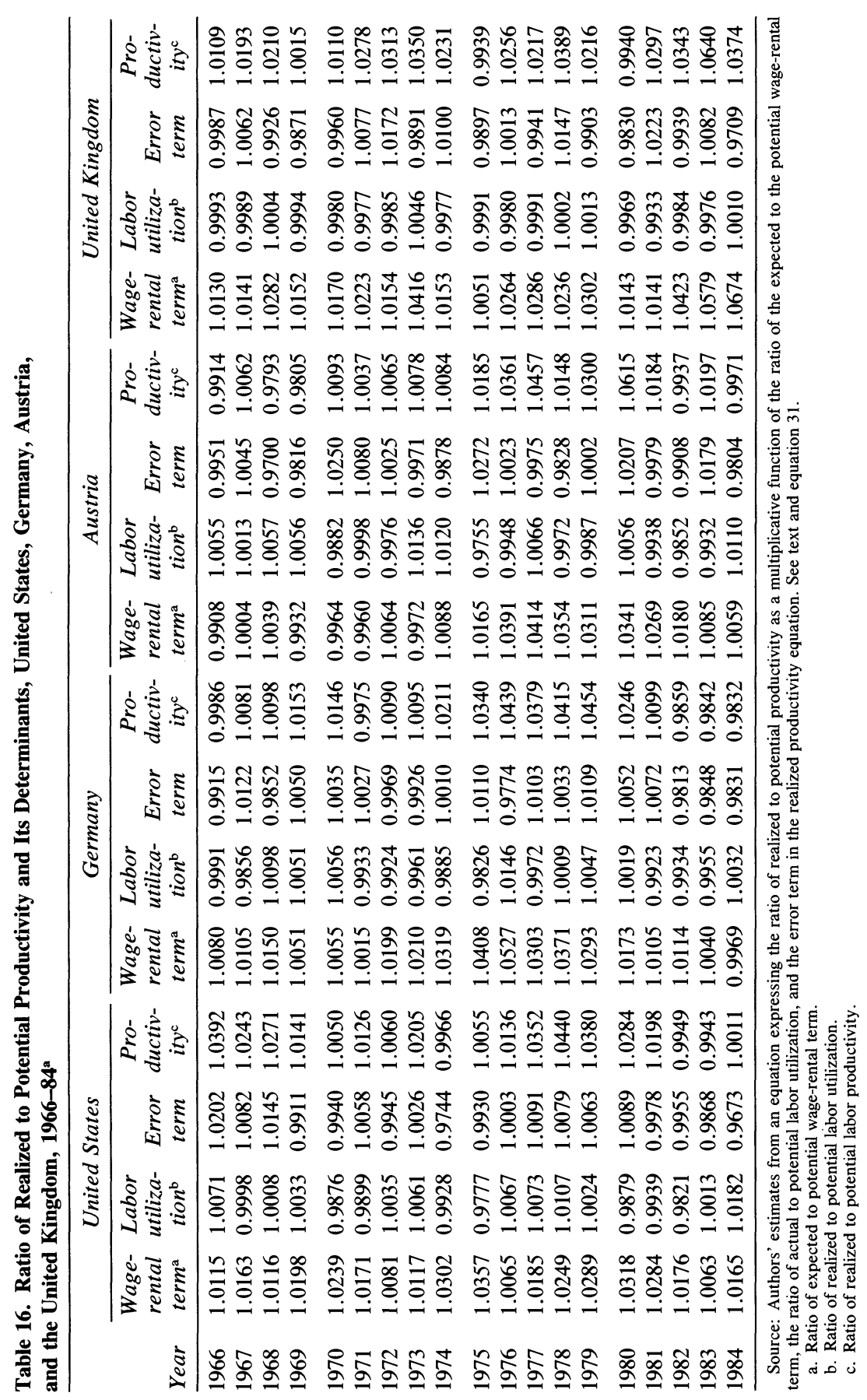


growth of total factor productivity is independent of realized capital formation. ${ }^{48}$ That is the basic reason for defining the potential output path as the equilibrium growth path that would be consistent with continuous full employment of both labor and capital.

Finally, what is the effect on measured labor productivity and investment if the real wage is above the full-employment level, as in figure 2? For the given output level positioning the labor demand function, realized labor productivity varies positively with the real wage, so that when the wage gap is positive, actual productivity exceeds potential productivity. By the same token, the desired capital-labor ratio, and hence actual net investment, is higher than it would be without a wage gap.

\section{Potential and Realized Productivity}

An equation similar to equation 31 governs the behavior of realized productivity as a function of the rate of technical progress, the expected wage-rental ratio, and the rate of growth of actual man-hours, measuring the intensity of labor utilization, plus a stochastic error term. As may be seen from table 14, the growth rates of potential and realized productivity are much the same, since they are equally affected by the underlying rate of technical progress; and the contributions of the other terms, and especially of the wage-rental ratio, are highly correlated. Clearly the trend rates of actual and potential productivity are quite similar and not strongly affected by the wage-rental gap. One expects to observe shortrun fluctuations about the trend of potential productivity, however, owing to wage-rental shocks and adjustment lags.

If the equations for realized and potential productivity are divided term-by-term, the result is an expression explaining the ratio of realized and potential productivity as a multiplicative function of the ratio of the contributions of the expected and potential wage-rental rates, the ratio of actual and potential labor utilization, and the error term in the realized productivity equation. The term for technical progress drops out because it is common to both equations. These measures are shown for each country from 1966 to 1984 in table 16.

48. This assumes that learning by doing through capital formation is an unimportant component of technical progress. 
The contribution of the wage-rental term depends on the size of the wage gap, since all other components of the wage-rental ratio cancel out, and on the elasticity of labor productivity with respect to the wagerental ratio, given by the estimated value of $\alpha$ in the production functionabout 0.25 for the United Kingdom and United States and 0.30 for Austria and Germany. A comparison of columns 1 and 4 for each country shows a high correlation between the wage and productivity gaps, as expected. However, fluctuations in labor utilization and stochastic disturbances also affect the productivity gap substantially in some years. Insofar as the association between the wage and productivity gaps is concerned, the principal point is that a positive productivity gap stemming from a positive wage gap is a symptom of labor market disequilibrium rather than a lasting productivity gain.

\section{Which Full-Employment Concept?}

Our analytical framework distinguishes between the classical and Keynesian components of excess unemployment. Traditionally the definition of full employment has allowed for a necessary amount of unemployment for efficient functioning of labor markets in the presence of internal migration, resource reallocation, seasonal fluctuations, and job search activities. It is this concept of frictional or structural unemployment that underlies Wachter's normalized unemployment measure of the natural unemployment rate as adapted for this study. ${ }^{49}$

The concept of the unemployment rate consistent with nonaccelerating inflation (NAIRU) also posits a necessary quantity of frictional unemployment, and in the absence of supply shocks the natural unemployment rate is conceptually the same under the two alternatives, as is clear from Milton Friedman's original definition. ${ }^{50}$ Measurement of the NAIRU from a Phillips curve is unusually sensitive to the precise

49. Wachter, "The Changing Cyclical Responsiveness of Wage Inflation."

50. "The 'natural rate of unemployment,' in other words, is the level that would be ground out by the Walrasian system of general equilibrium equations, provided there is embedded in them the actual structural characteristics of the labor and commodity markets, including market imperfections, stochastic variability in demands and supplies, the cost of gathering information about job vacancies and labor availabilities, the costs of mobility, and so on." Milton Friedman, "The Role of Monetary Policy," American Economic Review, vol. 58 (March 1968), pp. 1-17. 
specification of the functional relationship, however, as may be seen from the wide range of empirical estimates in the literature.

NAIRU estimates by David Coe and Francesco Gagliardi are shown in table $17 .{ }^{51}$ They offer two series that differ conceptually only in the specification of the trend rate of increase of import prices and that are nonetheless strikingly dissimilar when it comes to the estimated NAIRUs. The first set uses the actual growth rate of import prices in each subinterval to estimate trend changes in the terms of trade, whereas the second uses an average rate of growth calculated over the estimation period (longer than the total span covered in the NAIRUs) of the underlying Phillips curves. Thus the first set responds promptly to current and recent import price shocks, whereas the second smooths them over the entire estimation period. Also reproduced in the table are NAIRU estimates for several countries from other studies cited by Coe and Gagliardi, which again differ substantially from the others. ${ }^{52}$

These ambiguities stem partly from differing attempts to adjust for shifts in the Phillips curve in response to supply shocks. When the issue is viewed in terms of these NAIRU concepts, in other words, attention shifts from purely frictional unemployment to unemployment that is needed to offset the inflationary consequences of supply shocks. The concept of the natural rate has changed from a measure of unemployment necessary for microeconomic efficiency to one seeking to avoid accelerating inflation from demand management policies. In terms of our figure 2, the supply shock that raised the actual real wage above the fullemployment level is also assumed to have shifted the full-employment labor supply leftward to a level consistent with stable inflation, creating long-term equilibrium natural unemployment as well as disequilibrium classical unemployment.

The specification of the natural unemployment rate may markedly

51. David T. Coe and Francesco Gagliardi, "Nominal Wage Determination in Ten OECD Economies," Working Paper 19 (Paris: Organization for Economic Cooperation and Development, March 1985).

52. Estimates for the United States are from A. S. Englander and C. A. Los, "Recovery without Accelerating Inflation," Quarterly Review (Federal Reserve Bank of New York, Summer 1983), pp. 19-28; and S. Braun, "Productivity and the NAIRU (And Other Phillips Curve Issues)," Working Paper 34 (Board of Governors of the Federal Reserve System, February 1984). Estimates for other countries are from R. Layard, G. Basevi, O. Blanchard, W. Buiter, and R. Dornbusch, "Europe: The Case for Unsustainable Growth," Center for European Policy Studies, No. 8-9 (1984). 
Table 17. Comparison of Estimates of the Nonaccelerating Inflation Rate of Unemployment (NAIRU), Selected Periods, 1961-83

Percent

\begin{tabular}{|c|c|c|c|c|c|c|}
\hline \multirow[b]{3}{*}{ Country } & \multirow[b]{3}{*}{ Period } & \multirow{3}{*}{$\begin{array}{l}\text { Average } \\
\text { unemploy- } \\
\text { ment rate }\end{array}$} & \multicolumn{4}{|c|}{ NAIRU estimates } \\
\hline & & & \multicolumn{2}{|c|}{$\begin{array}{c}\text { Coe-Gagliardi } \\
\text { estimates }^{\mathrm{a}} \\
\end{array}$} & \multicolumn{2}{|c|}{ Other studies } \\
\hline & & & $(1)$ & $(2)$ & $(1)$ & (2) \\
\hline \multirow[t]{5}{*}{ United States } & $1961-69$ & 4.7 & $\ldots$ & . & 4.8 & 5.9 \\
\hline & $1967-69$ & 3.6 & 4.1 & 5.7 & $\ldots$ & 5.9 \\
\hline & $1970-73$ & 5.4 & 6.0 & 5.4 & 6.0 & 5.8 \\
\hline & $1974-81$ & 6.9 & 7.3 & 6.5 & 6.8 & 7.1 \\
\hline & $1982-83$ & 9.7 & 4.2 & 6.1 & $\ldots$ & 6.8 \\
\hline \multirow[t]{3}{*}{ Japan } & $1972-75$ & 1.5 & 1.2 & 1.2 & $\ldots$ & $\ldots$ \\
\hline & $1976-80$ & 2.1 & 1.9 & 1.9 & $\ldots$ & $\ldots$ \\
\hline & $1981-83$ & 2.2 & 2.3 & 2.3 & $\ldots$ & . . \\
\hline \multirow[t]{4}{*}{ Germany } & $1967-70$ & 1.0 & 0.9 & 0.7 & & \\
\hline & $1971-75$ & 1.8 & 1.6 & 3.3 & & \\
\hline & $1976-80$ & 3.6 & 3.1 & 2.4 & & \\
\hline & $1981-83$ & 6.3 & 8.0 & 3.6 & & \\
\hline \multirow[t]{4}{*}{ France } & $1966-70$ & 2.1 & . & . & & \\
\hline & $1971-75$ & 2.7 & 4.6 & 4.5 & & \\
\hline & $1976-80$ & 5.2 & 3.3 & 4.8 & & \\
\hline & $1981-83$ & 8.3 & 9.0 & 7.7 & & \\
\hline \multirow{4}{*}{ United Kingdom } & $1967-70$ & 2.2 & 2.6 & 7.1 & & \\
\hline & $1971-75$ & 3.0 & 7.2 & 4.2 & & \\
\hline & $1976-80$ & 5.4 & 7.3 & 7.6 & & \\
\hline & $1981-83$ & 10.6 & 5.9 & 9.4 & & \\
\hline \multirow[t]{4}{*}{ Italy } & $1966-70$ & 5.5 & 4.8 & 7.5 & & \\
\hline & $1971-75$ & 5.8 & 7.2 & 5.4 & & \\
\hline & $1976-80$ & 7.1 & 6.0 & 5.2 & & \\
\hline & $1981-83$ & 9.1 & 6.1 & 5.4 & & \\
\hline \multirow[t]{4}{*}{ Canada } & $1967-69$ & 4.2 & 3.8 & 6.4 & & \\
\hline & $1970-73$ & 5.9 & 4.1 & 4.7 & & \\
\hline & $1974-79$ & 7.2 & 7.2 & 5.8 & & \\
\hline & $1980-83$ & 8.5 & 6.9 & 7.4 & & \\
\hline \multirow[t]{3}{*}{ Austria } & $1969-73$ & 1.4 & 1.0 & 1.1 & & \\
\hline & $1974-79$ & 1.8 & 1.4 & 1.4 & & \\
\hline & $1980-83$ & 3.0 & 2.4 & 2.4 & & \\
\hline \multirow[t]{3}{*}{ Netherlands } & $1969-73$ & 2.5 & 2.2 & 3.0 & & \\
\hline & $1974-79$ & 5.2 & 5.4 & 4.5 & & \\
\hline & $1980-83$ & 9.3 & 10.6 & 8.7 & & \\
\hline
\end{tabular}

Source: Reproduced from Coe and Gagliardi, "Nominal Wage Determination in Ten OECD Countries."

a. The NAIRU estimates in column 1 are calculated using the actual rate of growth of import prices; in column 2 they are calculated using the average rate of growth over the estimation period.

b. For the United States the source is Englander and Los, "Recovery without Accelerating Inflation," in the first column and Braun, "Productivity and the NAIRU," in the second; for the other countries the source is Layard and others, "Europe: The Case for Unsustainable Growth." 
affect the estimated quantity of excess unemployment and its breakdown into classical and Keynesian components in our model. The full-employment wage, and hence the wage gap, is invariant to changes in the natural rate, since the latter is not a determinant of technical progress, capital deepening, or labor utilization, and hence does not affect the path of potential productivity. An increase in the natural rate does reduce the estimated full-employment labor supply, however, which means that the unchanged wage gap will account for a larger fraction of a reduced volume of excess unemployment. If a NAIRU specification is used, and it closely tracks the actual unemployment rate, as it usually does in empirical estimates, there is little or no disequilibrium unemployment.

Which concept should provide the basis for estimation of excess unemployment? We advocate the normalized unemployment rate underlying the preceding tables, especially in view of the large uncertainties involving even carefully prepared NAIRU estimates. To quote Coe and Gagliardi on the estimates reproduced above:

It must be noted that the confidence intervals around these estimates are likely to be very large reflecting imprecise coefficient estimates and mis-specification in the wage and price equations. For this reason, as well as the analytic fuzziness of the NAIRU concept when applied to economies out of long-run equilibrium, the policy relevance of the estimated NAIRU's may not be great. ${ }^{53}$

By providing a conservative estimate of the rise of the natural rate from demographic and internal forces, our analysis of excess unemployment focuses on the proximate causes of the rise of actual unemployment in the seventies and eighties, without attempting a problematic breakdown between the natural and classical components of wage-gap unemployment from supply shocks. The associated estimates of potential output also provide a superior capacity benchmark, since they allow only for changes in the amount of frictional unemployment required for economic efficiency. ${ }^{54}$

A similar approach is followed, incidentally, by Bruno and Sachs. ${ }^{55}$ It is true that they estimate a Phillips curve that allows for the effects of changes in the product wage gap, the terms of trade, and the growth rate of full-employment labor productivity on consumer price inflation at a

53. Coe and Gagliardi, "Nominal Wage Determination," p. 29.

54. Our estimates of normalized unemployment could be improved, however, by explicitly incorporating variables directly affecting frictional unemployment.

55. Bruno and Sachs, Economics of Worldwide Stagflation, chap. 10. 
given unemployment rate, and that embodies "a long-run threshold of unemployment (like a 'natural rate,' $U^{N}$ ). . . This $U^{N}$ is defined as the level of unemployment such that real wage growth is just balanced by trend productivity growth adjusted for terms-of-trade changes." ${ }^{56}$ When it comes to the unemployment consequences of supply shocks, however, these are estimated in a reduced form of actual unemployment on the wage gap and on real money balances as a demand factor. The relative importance of the wage gap and demand factors is then discussed in terms of their contributions to the increase of actual unemployment between 1965-69 and later subperiods, as in the updated findings of Bruno cited above. ${ }^{57}$ Our approach to accounting for the proximate sources of the rise of unemployment is clearly in the same spirit.

\section{Policy Implications}

What is the significance of our empirical measures for demand management policy? A full answer is beyond the scope of this paper, since it requires a complete model of the determination of wages, prices, and other key macroeconomic variables. However, some conclusions may be stated for the case where the real wage is not much altered by demand management, a case broadly consistent with normal cost pricing and cyclical history.

When excess unemployment is largely attributable to a demand gap, considerable scope is implied for demand management, even if the wage gap is substantial. The existence of a sizable wage gap is not prima facie evidence that classical unemployment is a dominant factor or that employment will not respond to demand expansion.

The gap between current and full-employment output is a quantitative estimate of the amount of output expansion needed to eliminate that portion of excess unemployment attributable to deficient demand at the

56. Ibid, p. 202. The wage equation necessary to identify the parameters of the naturalrate specification is not estimated by Bruno and Sachs, however, so no empirical measures of the natural rate are supplied in their study.

57. Bruno, "Aggregate Supply and Demand Factors." The same general point is also valid for the important multicountry study of C. R. Bean, P. R. G. Layard, and S. J. Nickell, "The Rise of Unemployment: A Multicountry Study," Economica, vol. 53 (Supplement, 1986), pp. S1-S22. They offer a similar reduced-form analysis of the role of demand and supply factors in the change in actual unemployment between 1956-66 and 1980-83 even though their model embodies a NAIRU. 
full-employment wage level. The amount of demand stimulus needed to close the output gap will of course depend on the multiplier properties in a given model or country and may vary with the policy instrument.

Although the utilization rate of full-employment output is a direct indicator of the output expansion required to attain full employment in a given year, the preferable target in a longer perspective is potential output, because capital as well as labor will be optimally employed along the natural growth path.

Neither concept involves a NAIRU estimate of the natural unemployment rate, for the reasons previously discussed. The existence of a large demand gap implies room for substantial expansion of employment at the given real wage and a correspondingly large degree of excess capacity to restrain price pressures, but it does not provide a direct estimate of the inflationary consequences of an approach to full employment.

Does classical unemployment pose special problems of macroeconomic adjustment that differ from those associated with Keynesian unemployment? To what extent can or should classical unemployment be offset by stimulating aggregate demand?

In a complete macroeconomic model based on imperfect competition, firms set prices as a markup on unit labor costs, the markup varying with demand conditions, so as to achieve given profit margins or rates of return. Demand expansion would therefore imply an attempt by firms to raise their markups in the hope of reducing real product wages and restoring or raising profit margins. If nominal wages are incompletely indexed to prices, real wages and classical unemployment may then be decreased along with Keynesian unemployment by expansionary demand policy.

To the extent that real wages are sticky in the face of price increases, however, firms' price-setting behavior will not easily remove a wage gap, and the rising price level may reduce aggregate demand through the Keynes or Pigou effects, offsetting part of the reduction in Keynesian unemployment for a given degree of demand stimulus.

The manner in which imperfectly competitive firms attempt to maintain profit margins also has implications for the efficacy of demand management to offset classical unemployment. While it is possible to increase labor demand at given factor prices by stimulating aggregate demand, the demand stimulus does not directly address the imbalance between firms' desired rates of return and their lower realized rates of return when there is a wage gap. When unemployment is classical and 
output is at the full-employment level, the wage gap should induce firms to raise prices, which may or may not bring down real wages. If real wages are sticky and the gap persists, stimulation of demand, while reducing excess unemployment, may add to the upward pressure on prices by raising capacity utilization. The inflationary consequences of a given wage gap may thus be accentuated by the demand stimulus.

To offset classical unemployment by augmenting aggregate demand, while at the same time holding down inflationary pressures, may therefore require that demand stimulus be accompanied by actions to sustain profits at acceptable levels-employment subsidies, investment subsidies, general subsidies to state enterprises, and so forth. While the longterm effects of such actions on economic efficiency may be undesirable, the approach may nonetheless prove superior to efforts to eliminate classical unemployment by direct attacks on wage gaps.

It is important to bear in mind that a full-employment macroeconomic equilibrium is not assured by having the real wage at the natural level. Output must also be at the full-employment level. In a framework of imperfect competition in which output is demand determined, an incomes policy aimed at directly reducing the real wage to the natural level may lead to a level of aggregate demand that falls short of or exceeds fullemployment output, in which case demand management must be used in conjunction with the incomes policy to achieve full employment. Again, a full model of aggregate supply and demand is required to study the efficacy of incomes policies, and the appropriate mix of incomes and demand management policies may depend on the particular historical and institutional circumstances.

\section{Conclusions}

Our new measures identify demand gaps as the major source of excess unemployment during 1967-74 in all the countries in our sample except the United Kingdom. The United States, Germany, and the United Kingdom experienced chronic excess unemployment after 1974, but Austria escaped their fate until 1981-84. In the United States, the wage gap has increased in importance especially since 1974, but aggregate demand has remained the dominant determinant except in isolated years. The wage gap in Germany waxed and waned during 1973-84, but classical unemployment was never the dominant factor. Excess unemployment 
was minimized in Austria during the 1970s by offsetting demand and wage gaps. Although not the dominant component in most years since 1974, classical unemployment has usually been substantial in the United Kingdom. The sharp run-up of unemployment in all the countries during the 1980s was induced primarily by deficient demand, although it was substantially augmented by large wage gaps in the United Kingdom and the United States.

Hidden unemployment is quantitatively important in all the countries, so that elimination of the employment shortfall would reduce unemployment by a considerably smaller amount in most years. This is especially true of Austria and the United States, where the employment elasticities of labor force participation are larger than they are in Germany and the United Kingdom.

Inverse responses of average hours substantially mitigated the employment improvements from the simulated wage reductions in all countries except the United States, where the induced rise in hours was small. The implication is that empirical studies that abstract from endogenous changes in hours may seriously overestimate the wage elasticity of employment.

The finding of large and growing demand gaps in the 1980s implies that expansionary monetary and fiscal policies would act to reduce unemployment in these countries. As mentioned, our partial-equilibrium measures provide quantitative estimates of the output expansion that would eliminate Keynesian unemployment were the real wage invariant to demand expansion. Since the real wage is an endogenous variable, however, the classical component of unemployment could increase or decrease in the process of demand expansion, and a complete policy prescription is beyond the scope of this paper.

Irrespective of equilibrium NAIRU calculations, import price pressures in the European countries have been eased substantially by reduced oil prices and a weak dollar, and our low potential utilization estimates for Germany and the United Kingdom indicate a considerable margin for expansion without undue pressure on markups. Finally, if there is an element of hysteresis in the natural rate, as in the insider-outsider theory of Blanchard and Summers, a demand expansion that reduced actual unemployment would also reduce the NAIRU. ${ }^{58}$

58. Olivier J. Blanchard and Lawrence H. Summers, "Hysteresis and the European Unemployment Problem,'” Working Paper 1950 (National Bureau of Economic Research, June 1986). 


\section{Comments and Discussion}

Stephen M. Goldfeld: The interesting paper by Robert Coen and Bert Hickman is motivated by one of the important questions of this or any other day-the sources of unemployment both here and abroad. The paper explores the intuitively appealing notion that both aggregate demand and real wages have a role in the explanation. More specifically, it provides a methodology for sorting out the relative effects of each of these variables and carries out this "unemployment accounting" for four countries. In discussing the paper, I first briefly examine some features of the underlying model. I then turn to the question of the potential sensitivity of the unemployment accounting to alternative assumptions. Finally, I consider the somewhat harder issue of what questions the numbers and methodology are providing answers to.

Coen and Hickman characterize their model as supplying a framework consistent with the assumption of imperfect competition in the presence of uncertainty. While this is generally a fair characterization there are a few elements of inconsistency that are worth noting. One feature of the model is that capital and labor inputs are viewed as chosen so as to minimize the cost of producing the expected level of output. Presumably more relevant is the choice of inputs so as to minimize expected cost, but this is a rather minor inelegance. A bit more inelegant is the fact that adjustment costs are posited to lead to separate partial adjustment models for capital and labor, although this too is a feature of other models.

The treatment of adjustment raises some other issues. Given the partial adjustment of factor inputs in the Coen-Hickman model, in the short run firms end up off their long-run production function. Firms compensate for this by endogenously adjusting the utilization of capital 
and labor. Whether this makes sense in all circumstances obviously depends on one's views of the underlying technology, that is, of the scope for ex post substitutability between capital and labor.

The endogeneity of capacity utilization also raises a question about the nature of the underlying price equation. In the Coen-Hickman model prices are determined by a markup over normal unit labor costs but also depend on import prices and capacity utilization. The presence of the latter variable suggests that price-setting behavior should therefore take account of the adjustment costs driving the partial adjustment of inputs. This interconnection between pricing and factor adjustments seems to be missing from the model. On the other hand, since the price equation is ignored in the unemployment accounting, except for the possible reverse effect of the pricing strategy on the adjustment of capital, this point is somewhat moot.

On the whole, while one may quibble with various features of the Coen-Hickman model, these are hardly the major issues in the context of the paper.

A more serious set of questions concerns the details of the unemployment accounting and the potential sensitivity of the numerical results to alternative assumptions, either as to the specification of the estimated equations or as to the general structure of the model. To begin with, even taking the specification of the model as given, the stochastic nature of the estimated equations means that the unemployment accounting is subject to uncertainty. Unfortunately no measures of this uncertainty are provided, so we remain unsure as to the precision of the split into wage and demand gaps. Once we recognize the possibility of alternative specifications, the robustness issue is even more critical. That this is of some potential relevance is suggested by the observation that some of the key elasticities in the present model appear noticeably different from those of other researchers. Another example is provided by the natural rate of unemployment. In the present paper, the natural rate is determined by purely demographic considerations and is driven by the prime-age male unemployment rate. Needless to say, there are alternative ways to generate this benchmark rate and, as Coen and Hickman acknowledge, the particular numbers used will have a direct effect on the accounting exercise.

A rather different sort of sensitivity issue is raised by the treatment of capital goods prices in the model. To use the model one needs the real 
wage expressed in terms of both consumer and capital goods prices, and, as a simplification, Coen and Hickman assume that one can ignore the differential trend in consumer and capital goods prices along the potential path. By their own numbers, admittedly for the actual rather than potential path, this assumption appears a bit problematic.

A closely related issue concerns the adjustments made in response to the first oil shock. The unanticipated increase in import prices is characterized as raising the prices of investment goods relative to money wages and is dealt with by imposing on the full-employment path an exogenous downshift in the real wage of 7 percent. As one justification for this, Coen and Hickman state that the oil shock induced a lasting increase of about 5 percent in the ratio of the price of capital goods to final output. It is clear that the initial effect was of this order of magnitude, at least if one uses implicit deflators rather than fixed-weight indexes. Indeed, using the latest GNP data, the relevant ratio goes from 0.929 in 1973 to 0.976 in 1975 . However, by 1984 , the ratio has fallen to 0.915 , below its level in 1973. While these numbers are not definitive as to what would happen along a potential path, the assumed permanent nature of the changes is open to some doubt. Indeed, the authors allow for a second shift in the 1980s, arising this time from the dollar's appreciation. A perhaps more satisfactory way to deal with this issue would be to model explicitly the behavior of investment good and final good prices in response to import price changes.

A somewhat different issue concerning the unemployment accounting is the treatment of the so-called carryover unemployment. Because of the existence of adjustment lags, even if output and the real wage are at their full-employment values, the economy will not be in long-run equilibrium unless last period's man-hours were also at the full-employment level. The part of unemployment attributable to this lagged adjustment is carryover unemployment. Although in some earlier work Hickman reported carryover unemployment separately, in the present paper it is lumped in with unemployment due to inadequate demand. While this is to some extent semantics, I would have preferred the earlier treatment since it strikes me as a bit unreasonable to contemplate driving output above potential output to compensate for past shocks and for policy errors. As this suggests, one's preferred treatment of carryover unemployment is related to the more general issue of how one interprets the results of an unemployment accounting exercise. 
Broadly put, the key question is what we learn by an allocation of unemployment into real wage and aggregate demand components. Coen and Hickman suggest that such an allocation indicates the "proximate causes" of unemployment. They also indicate that their allocation utilizes demand functions conditional on real wages and output. Some care is needed in interpreting this statement because however Coen and Hickman choose to regard output and the real wage, the data they utilize emerge from a real world economy where output, the real wage, and the variables they analyze explicitly are all jointly endogenous. Potential technicalities aside, it is somewhat unclear as to the sense in which the Coen-Hickman calculations yield proximate causes. Other attempts at unemployment accounting have considered a wider range of potential explanations such as unemployment benefits, union power, skill or regional mismatches, and public unemployment, to name a few. How these sorts of considerations should be integrated with wage gaps and demand gaps is not really clear, in part because the unemployment accounting exercise does not seem to give answers to any well-posed question.

What lies behind economists' interest in unemployment accounting is the possibility of extracting a message for policymakers. One temptation is to leap from Coen and Hickman's finding that unemployment is due to a demand gap to the conclusion that aggregate demand management is called for. The companion temptation is to conclude that a real wage gap may call for other sorts of policies. Unfortunately, in the absence of an explicit model as to how policy operates, neither of these conclusions may be warranted. Output may be below potential, and there may be limited scope for demand management. Alternatively, there may be a wage gap that is fully curable by aggregate demand management. Robert Solow, for example, has provided an illustrative model in which the real wage is too high at the same time that output is below potential but where expansionary monetary policy can cure all gaps. ${ }^{1}$

On balance, then, while tantalizingly interesting, the sorts of numbers presented by Coen and Hickman need to be supplemented with more structure to make them fully interpretable and more useful for policy purposes.

1. Robert M. Solow, "Unemployment: Getting the Questions Right," Economica, vol. 53 (Supplement, 1986), pp. S23-S34. 
James Tobin: In the best Brookings Panel tradition, this paper is motivated by crucial current issues of macroeconomic diagnosis and prescription and brings sophisticated analytical and empirical tools to bear on them. Is the high unemployment of the 1980s "classical" or "Keynesian"? Is it attributable to stubbornly excessive real wages? Or to shortfalls in effective demand? Would expansionary fiscal and monetary policies just cause inflation? Or would they add to real output and employment? These timely questions are especially relevant to Europe, but they apply also to Japan, where the unemployment is disguised, and to the United States, where the economy has settled into rates of unemployment and excess capacity higher than those in previous cyclical recoveries.

I applaud Coen and Hickman for their audacious and ingenious attempt to quantify concepts so important in macroeconomic theory and policy, especially because they confirm my own priors that most unemployment beyond the rates of the late 1970s is Keynesian.

Those bouquets are a sincere prelude to the doubts I am about to express.

Do the authors really answer the questions that concern policymakers? The Euro-pessimists or Euro-hypochondriacs forswear demand stimulus because they believe it will be inflationary. They think that businesses require higher profit margins to expand production, that workers won't permit them, that unions will demand still higher real wage rates if prosperity enhances their bargaining power, that the NAIRU has shifted many points in the wrong direction. Sometimes the European position appears to be that demand expansion is inflation-safe only if it is naturally generated by export markets or spontaneous domestic demand, never if it is contrived by government.

The authors' findings will not reassure Euro-pessimists who think like that. Coen and Hickman tell them they have a lot of Keynesian unemployment-the more so because some is "hidden"-but they cannot assure them that Keynesian remedies will be noninflationary. The authors' full employment, which corresponds to their "natural-rate" unemployment, is not the NAIRU. I endorse the distinction in principle, without understanding why the 3 percent unemployment rate of males aged forty-five to fifty-four in 1956 is the benchmark for full employment in the United States. The authors do not say what would happen to money wages, real wages, and prices if demand stimulus were undertaken to reach full employment. Their findings should be somewhat reassuring, 
because they show there is plenty of room in the economies they study to enable production to respond to demand. But they don't dispel the fears of sectoral bottlenecks, structural rigidities, and distributional conflicts that Euro-pessimists cite as obstacles to noninflationary macroeconomic expansion.

What is missing from the authors' model is a relationship between the Bruno-Sachs wage gap and the Okun output gap. Coen and Hickman decompose shortfalls in employment and production into classical and Keynesian components. Their additive decomposition is simple and neat, and their idea that the two types of unemployment can coexist is appealing. But the implication that the demand constraint could be removed without affecting the real wage is suspect.

I sketched above the likely suspicions of a Euro-pessimist. A General Theory Keynesian might have quite the opposite suspicion. He could say that the real wage is high because demand is short. Thanks to competition among employers, even when there is an overall effective demand constraint, workers lucky enough to have jobs are paid far more than their reservation wages. Expansion itself will dissipate these rents. The unemployment may look classical, but the wage gap is a mirage that will vanish en route to prosperity.

Which scenario, pessimistic or optimistic, applies to the countries and periods under study is an empirical question. Theory tells us little about relations among these variables in disequilibrium. Economic and political institutions matter, and the findings are likely to differ among national economies. Conventional wisdom a few years ago was that nominal wage inertia characterized the United States and United Kingdom, while continental European economies suffered from real wage inertia. Robert Gordon questions that in a recent paper, and I will let him speak for himself. ${ }^{1}$

I allow myself a digression from the authors' text. The failure of inflation to fall precipitously in economies where unemployment has been so high so long suggests to some observers that the NAIRU has risen many points. If you are sure of the slope of the short-run Phillips curve, you will explain the slow attrition of inflation in the 1980s by a large adverse shift in the curve. The implication is that demand expansion, starting from unemployment rates around 10 percent, will accel-

1. Robert J. Gordon, "Productivity, Wages, and Prices Inside and Outside of Manufacturing in the U.S., Japan, and Europe," European Economic Review, vol. 31 (April 1987), pp. 685-733. 
erate prices. I find the conclusion unconvincing, given the absence of recent experience with demand expansion. Maybe the short-run Phillips curve is nearly flat in the previously virgin territory of 1980 s observations; maybe the paths of wages and prices are pretty much detached from the size of the Okun gap.

The potential output path is crucial to the calculations of the real wage and output gaps and of the decomposition of unemployment into the two types. The path, as I understand it, is essentially a track familiar in neoclassical growth theory with one product and two factors, labor and capital. Of the family of tracks consistent with the technology, the authors' path is the one that has an after-tax return on capital of 6 percent. The related "rental cost of capital" is, however, not strictly constant but varies with the tax treatment of depreciation and investment. It is gratuitously assumed that saving would always match the capital accumulation implied by the path.

The uniqueness of the potential output path and the neglect of the $I S$ equation seem to me to limit the usefulness of the paper for policy. How demand stimuli might eliminate Keynesian unemployment, and how the mix of monetary and fiscal policy might affect potential output, cannot be analyzed. I should think that how the capital investment implied by the authors' model is financed would affect real interest rates and the growth path itself.

The authors' potential output does not depend upon the history of actual output. No matter how much and how long actual output falls short, its shadow marches on in splendid detachment. The authors blithely observe that deficiencies of capital and labor inputs can always be repaired in the future. Here again, the absence of a saving function is crippling. It may or may not be so that savers, as well as investors, will eventually accumulate wealth and capital to the same multiples of potential output whether interrupted by recessions and depressions or not. But surely after a decade of stagnation it would take a long time to build a capital stock of normal size. Presumably there would also be lasting damage to human capital. Now that the profession has rediscovered the fancy word hysteresis, it is respectable to mention effects of this kind.

The model assumes constant-returns-to-scale Cobb-Douglas technology, with capital exponent $\alpha$ and Hicks-neutral progress at rate $\beta$, thus Harrod-neutral labor augmentation at rate $\beta /(1-\alpha)$. Neither $\beta$ nor the rate of growth of the natural labor force is constant. Nonetheless the 
exogenous input that drives the growth of potential output is augmented labor. The equilibrium capital stock along the path corresponds to the ratio $k^{*}$ (my notation) of capital to augmented labor that yields the required rental. This ratio will be roughly constant.

The same $k^{*}$ determines the near-constant real wage $w^{*}$ (my notation) of augmented labor, from which can be derived the real wage for natural labor, growing at rate $\beta /(1-\alpha)$. The $w^{*}$ path could be regarded as the reference path for calculating the wage gap and classical unemployment. Suppose the actual productivity-adjusted wage $w$ is higher than $w^{*}$. Assume with the authors that the supply of savings is perfectly elastic so that the rental cost of capital $q$ (the authors' $q$, not mine) stays put. We know that in Cobb-Douglas technology $k=[\alpha /(1-\alpha)](w / q)$, and of course $k^{*}=[\alpha /(1-\alpha)]\left(w^{*} / q\right)$. A higher wage-rental ratio requires a proportionately higher $k$ and implies less $L$ or more $K$ for any given output.

The cost-minimizing response of a typical firm to a 1 percent increase in the wage-rental ratio is, as just argued, to raise $k$ over $k^{*}$ by 1 percent. Producing the same output as before, the firm would use $(1-\alpha)$ percent more capital and $\alpha$ percent less labor. The latter is the authors' estimate of the classical unemployment due to the rise in the wage relative to the rental cost of capital. But it is not the profit-maximizing solution. At that output, the firm would be making losses unless the product price rose by $(1-\alpha)$ percent relative to both the new wage $w$ and the rental $q$. In terms of product, the wage gap would be only $\alpha$ percent, and the rental cost would have fallen by $(1-\alpha)$ percent. It is hard to conceive a model of saving and investment that would, with income unchanged and capital's return lower, provide the additional capital in the short or long run.

The response of employment to a real wage increase involves not only substitution of capital relative to labor (higher $k$ ) but also adjustment of output. Economists who have emphasized the recent importance of classical unemployment have argued that excessive real wages limit the supply of output even when it is below potential. Were there a positive wage gap at or below full-employment equilibrium, firms would find it unprofitable to produce that much output and offer that much employment. In contrast, profitability is not an effective constraint in the authors' model; output is always constrained by demand.

An easy way to see this difference in the role of profitability is to consider the special case where the supply of capital $K$ is inelastic. As 
conceived by the authors, classical unemployment would be zero. An increase in the real wage would simply drive up the rental cost of capital until firms desired to produce the fixed, demand-constrained output with the same input of labor, that is, until the incentive to substitute one factor for the other was removed. Of course, if firms were just breaking even before the wage increase, they would now be running losses. The authors assume that somehow firms will find it profitable at the margin to produce up to the demand constraint.

Traditional classical unemployment, on the other hand, would be very large. Profitability, not demand, would become the effective constraint. Full profit-maximizing adjustment to a 1 percent real wage increase would require a decrease of $1 / \alpha$ percent in employment and of $(1-\alpha) / \alpha$ percent in output -4 percent and 3 percent, respectively, with the authors' estimate of $\alpha, 0.25$. It is in the nature of classical unemployment, in contrast to Keynesian unemployment, that it is due to real wage rigidity, so that a rise in the nominal price of output offers no escape from this scenario.

In general, the relationship between output prices and capital goods prices must be made explicit. In a one-product model, capital investment is simply one use of current output, which otherwise can be consumed. Movements in the product price do not alter the rental cost of capital. If operation of the existing capital stock is unprofitable, accumulation of capital will be unprofitable. As the stock is run down by depreciation, further reductions in output and employment will occur. A two-sector model, distinguishing capital goods production from consumer goods production, would be a cleaner way to proceed. The authors' use of capital goods prices as numeraire leads to confusion in defining wage gaps.

Classical unemployment has traditionally meant not just rigidly high real wages but also concurrent shortage of capital and, in a closed economy, of accumulated savings. Coen and Hickman simply wave that constraint away. If the capital stock can be assumed to adjust as needed to preserve output in the face of a wage gap, why not go further and assume it can adjust enough to preserve employment? A 1 percent increase in $K$, with appropriate reduction in capital cost to preserve profitability, would validate the 1 percent increase in the real wage with no loss of employment and an $\alpha$ percent gain in potential output. 
Suppose the economy shows by the authors' calculations both kinds of unemployment. The authors say that demand stimulus can remedy the Keynesian unemployment while the wage gap remains. Their decomposition of unemployment assumes that during the demand and output expansion, capital accumulation will be greater than in the absence of the wage gap. Investment will include "deepening," substitution of capital for labor, as well as "widening." This scenario is not subject to my objection above if the expansion itself can generate the necessary extra saving. That depends on the nature of the demand stimulus; a Reagan-Volcker fiscal-monetary mix could hardly be expected to do the job. On the investment side, one might doubt that in times of excess capacity and high real wages businesses will feel prepared both to expand capacity and to install labor-saving equipment.

A specific problem the authors faced was to modify their potential output track to allow for the impact of the energy shock of 1973-74. I am mystified by their resolution of this problem. One obvious step is to reduce the estimated rate of progress $\beta$ in the production function to allow for the lower growth of productivity observed, whatever its cause, after 1974. An additional possibility would be a one-shot reduction in the scale constant $A$ in the production function. However, it is not clear to me why an increase in the relative price of oil and energy should lower the capacity of domestic industries, including energy producers, to add value at constant prices. I don't see the relevance of the adverse shift in external terms of trade. I don't see why a jump in energy prices is modeled as a jump in capital goods prices necessitating a once-for-all decline in potential output in order to maintain the required return on capital.

In effect, what the authors appear to have introduced is a direct oneshot 7 percent downward adjustment of the equilibrium product wage. The result is a larger wage gap and classical unemployment, despite the fact that in the United States actual real wages, whether in terms of the authors' numeraire, capital goods, or of consumer goods, were falling significantly. It is neither contradictory to the authors' own concepts nor otherwise unreasonable to regard much of the unemployment in the United States in 1976-82 as Keynesian rather than classical unemployment, tolerated and generated by the monetary authorities to oppose the inflation brought by supply shocks and other events. 
The authors say that their model is based on imperfect, not pure, competition. Operationally, this is their justification for deriving factor demands from cost minimization rather than profit maximization, and for assuming firms are always demand-constrained.

I conjecture that Coen and Hickman have in mind something like the following as the way imperfect competition enters their model of potential output: a typical firm, a price-setter in product markets but a price-taker in factor markets, does not equate the marginal product $(M P)$ of labor to the real wage or the $M P$ of capital to its rental cost. The firm equates the marginal revenue product of each factor to its price. The $M R P$ in each case is $M P /(1+\mu)$, where $\mu$ is the markup in proportion to marginal cost. For the long-run calculations relevant to the growth track, constant returns to scale imply that marginal cost equals average cost and is constant. The markup $\mu$ can also be identified as the "degree of monopoly" and is equal to $-1 /(1+\eta)$, where $\eta(<-1)$ is the elasticity of demand for the firm's product with respect to its relative price. For the short run, the authors assume a markup over labor cost alone. Since wage cost is normally a fraction $(1-\alpha)$ of total cost per worker, I suppose this markup is $(\mu+\alpha) /(\eta+\alpha)$.

These markups, related to the degree of monopoly, bring monopolyrent incomes. They would have to be taken into account in a complete model, particularly in relation to consumption, saving, and taxation. However, a serious imperfect-competition model would not assume constant returns to scale for an individual firm. It would assume instead that a firm has increasing returns because of fixed costs required to establish and maintain product differentiation. Then the markups could be partially or wholly swallowed by those costs, as in Chamberlinian monopolistic competition.

In distinguishing their model from other disequilibrium macroeconomic models, the authors assert, "Keynesian and classical unemployment may coexist rather than occurring in separate regimes." Evidently, a separate classical regime is ruled out by the assumption of imperfect competition, since firms are always constrained by effective demand, with price exceeding marginal cost. Even in full-employment equilibrium such a firm would want to satisfy at prevailing prices additional demand due to an outward shift of its demand curve. But if all firms, all typical, tried to do so, the aggregate supply constraint would bind. It, not demand, is the effective constraint. The situation is not so different in 
the purely competitive model. There too, given constant returns to scale within firms or by multiplication of firms, output will respond to new demand at prevailing prices if and only if economywide resource supplies permit. Likewise in both cases individual firms may or may not be in local marginal-revenue-equals-marginal-cost situations.

Macroeconomic disequilibrium models, whatever their microfoundations, should not suggest that outputs and sales of individual firms are rationed. Both demand and supply constraints should be modeled as economywide limits that lead individual firms to decide not to produce or sell more.

My final comment refers to the authors' model of adjustments of employment and capital stock to their desired values. They talk of adjustment costs but do not explicitly introduce them. They use separate annual rates of stock adjustment for the two inputs. The desired stocks toward which the firm moves are derived from current values of output (demand) and factor prices, even though the firm will not reach those targets for many years. The labor adjustment is the faster, but it surely does not minimize costs along the way to employ labor as if the capital adjustment were complete when in fact it is not. An attractive feature of the model is the explicit distinction between numbers employed and hours of work. Why can't short-run adjustment of labor input be made in hours of work? Surely the proper strategy is to find a desired path of employment, hours, and investment, given the expected path of demand, such that the present value of costs, production plus adjustment, is minimized.

\section{General Discussion}

Robert Gordon questioned the very low natural rates of unemployment calculated for the three European countries by Coen and Hickman. He argued for defining the natural rate of unemployment as the NAIRUthe rate consistent with steady inflation-rather than in terms of labor market efficiency as the authors attempt to do. His own estimates for Europe as a whole based on wage and price equations show the 1984 natural rate to be in the vicinity of 6.0 to 6.5 percent, rather than the 1.0 to 2.0 percent Coen and Hickman assume for Germany, Austria, and the United Kingdom. 
Katharine Abraham suggested that the authors' estimates of the natural rate should consider factors other than demographics that may have affected the volume of frictional unemployment. She noted that in the United States and the United Kingdom, the inverse relationship between prime-age male unemployment and vacancies has shifted outwards over time, suggesting that, at least in these two countries, other sources of frictional unemployment have grown in importance.

Edmund Phelps explained why, even if one agreed with the authors that Keynesian shocks generally explain the lion's share of employment fluctuations, it does not follow from their analysis that the severe 1980s slump in Europe is predominantly Keynesian in origin. The derived demand for labor curve to which Coen and Hickman refer-their $L D-$ may have shifted down in this decade due to the increased markup desired by customer-market firms in response to the sharp rise in real interest rates, as argued in a recent paper by Phelps and J.-P. Fitoussi, rather than because of Keynesian shocks. ${ }^{1}$

Gordon remarked that the absence of dynamic wage and price equations limits the usefulness of Coen and Hickman's approach. Even though current real wages may not be far out of line, they may have been reduced in response to economic slack. Policymakers may fear that they would rise sharply if aggregate demand were now stimulated.

Martin Baily commented that the authors' decomposition of "excess" unemployment into classical and Keynesian components is extremely sensitive to assumptions about what is fixed and what is allowed to vary. As Coen and Hickman note in their paper, in a simple model with CobbDouglas production and no adjustment lags, the output-constant elasticity of demand for labor equals the inverse of capital's share if the capital stock is assumed fixed, but equals capital's share if the rate of return on capital is held constant while the capital stock is allowed to vary. If capital's share is assumed to be about 0.25 , the demand for labor is sixteen times more elastic under the first assumption than under the second.

1. J.-P. Fitoussi and E. S. Phelps, "Causes of the 1980s Slump in Europe," BPEA, 2:1986, pp. 487-513. 